\title{
LA EVOLUCION DE LA ESPADA EN LA SOCIEDAD CATALANA DE LOS SIGLOS XI AL XIII
}

\author{
POR \\ MARIA VICTORIA CIRLOT
}

\section{INTRODUCCIÓN}

EL estudio del armamento tiene su origen en las mismas exigencias de la historia social. Cada vez más, se hace inevitable la minuciosa reconstrucción de aquellos elementos materiales que hicieron posibles las sociedades guerreras ${ }^{1}$. Hasta el momento, los estudios acerca del armamento son muchos y muy importantes; sin embargo, considero fundamental someter la «historia del armamento» al método de la historia social. Y aquí reside una de las diferencias fundamentales entre nuestra investigación y los demás estudios acerca del armamento. No se le concederá al armamento un valor autónomo $\mathrm{y}$, por tanto, no será estudiado desde una perspectiva fenomenológica, sino que, por el contrario, se analizará en función de la sociedad. En consecuencia, se introducirá dentro de un período dotado de una homogeneidad social, que, en nuestro caso, será la sociedad feudal de los siglos xI al xiII. $\mathrm{Si}$ en esta época la guerra configuró toda una forma de vida y una cosmovisión determinada — tal y como afirma G. Duby ${ }^{2}$-, es obvio que gran parte de los esfuerzos de intelección de dicha actividad deban volcarse en su descripción material. Asimismo, el estudio riguroso de los grupos sociales de la época deberá venir precedido de un conocimiento preciso del propio utillaje que formaba su imagen. Sin duda

${ }^{1}$ Con ello no hago sino intentar seguir los presupuestos metodológicos que G. Dusy ha establecido para la configuración de una historia social: «La historia social debe mantenerse atenta a todos los vestigios del pasado, a los restos de utensilios y de equipo encontrados en las excavaciones, a todos los indicios de los antiguos hábitats humanos que subsisten en la apariencia actual de las zonas rurales y urbanas, en definitiva a todo aquello que pueda traslucirse a través de la observación de un santuario de peregrinación de la composición de un grabado, del ritmo de una estrofa gregoriana o de una concepción del universo conservada a través de las múltiples formas de la creación artística», en Les sociétés médiévales: une approche d'ensemble, Annales XXVI, núm. 1, enero-febrero 1971 (trad. esp. en Anagrama, 1976, pág. 11).

2 Esta idea la expuso G. DuBy de forma admirable en Le dimanche de Bouvines, nrf Gallimard, 1973, pág. 25 especialmente, así como en Guerre et société dans l'Europe féodale, en «Concetto, storia, miti e immagini del Medio Evo», a cura de Vittore Branca, Firenze, Sansoni, 1973, pp. $473-483$ fundamentalmente. 
alguna, es tarea urgente del historiador la descripción formal de aquellos hombres que, situados en el vértice de la sociedad, se cubrían del hierro que la avanzada tecnología de la época había logrado fabricar.

Pero, con frecuencia, tareas extremadamente sencillas, tales como una simple descripción, se tornan muy complejas cuando su objeto de análisis pertenece ya a un pasado muy lejano. Los restos del armamento que se conservan de la época feudal son muy escasos y no es posible lograr a partir de ellos una imagen que pretenda ser globalizadora. Por ello se impone recurrir a otras fuentes que, si bien impiden un conocimiento directo del objeto de análisis, hacen posible, en cambio, una reconstrucción de conjunto. A tales efectos parece que la iconografía es la fuente idónea. Podría objetarse que la plástica de los siglos XI al XIII es la menos indicada para la reconstrucción de objetos reales y cotidianos; $y$, sin lugar a dudas, si hay un arte que imagina y sueña, ése es el románico. Sin embargo, podemos afirmar que en lo que respecta al armamento el arte románico se caracteriza por una fidelidad absoluta a la hora de su representación. Y ello lo hemos podido comprobar en un primer acercamiento al estudio del armamento. El análisis de la espada en la Cataluña feudal, que seguidamente expondremos, ha sido posible gracias a las numerosas representaciones plásticas que la Cataluña actual conserva de su arte románico ${ }^{3}$. El estudio de la evolución formal de la espada catalana ha constituido un primer nivel de acceso al tema del armamento feudal y, al mismo tiempo, ha advertido acerca del inmenso valor simbólico que dicha arma ofensiva poseyó en la sociedad feudal ${ }^{4}$. En este sentido, esta primera investigación abre dos vías de análisis paralelas: 1, por un lado, el estudio de la espada y su tipologización a través de la iconografía confirman la posibilidad del análisis de las demás armas, tanto ofensivas como defensivas, por medio de esa misma fuente; 2 , de otro lado, un estudio interpretativo de cada arma y de su utilización a través de las fuentes artísticas y literarias podría resultar de gran ayuda a la hora de precisar los distintos niveles de estratificación de los diversos grupos sociales. En este sentido, el tema de la espada ofrece un campo vastísimo de posibilidades, y una de las metas fundamentales consistiría en verificar la hipótesis establecida por K. Bosl de que la espada constituyó un signo diferenciador entre los grupos sociales, posiblemente escindidos entre los portadores de espadas (Schwerttragenden) y los no portadores de es-

${ }^{3} \mathrm{El}$ estudio que aquí presento es un resumen de mi tesis de licenciatura: $L a$ evolución de la espada en la sociedad catalana de los siglos XI al XIII, dirigida por el Prof. J. E. Ruiz Domenec, y leída en la U. A. B., en junio de 1977.

${ }^{4}$ En la segunda parte de mi tesis de licenciatura, op. cit., intenté una aproximación al sentido sacro y simbólico de la espada en la sociedad feudal. 
padas ${ }^{5}$. Estos dos niveles de análisis constituyen el motivo guía de nuestra actual investigación ${ }^{6}$. De cualquier forma, por el momento, sólo estamos en condiciones de responder a la pregunta de cómo fueron las espadas en la Cataluña de los siglos XI al XIII.

\section{ANÁlisis dE LAS FUENTES UTILIZADAS}

Cualquier estudio de investigación que ha tratado el tema de la espada se ha basado para ello en piezas arqueológicas ${ }^{7}$. Es cierto que los especialistas en armamento recurren en muchas ocasiones a fuentes paralelas (como el arte, por ejemplo) para apuntalar y fechar los restos de las piezas reales ${ }^{8}$. Pero, hasta el momento, la iconografía no ha sido utilizada como documento único para el estudio del armamento. Esta será la diferencia específica entre esta investigación y los demás estudios sobre espadas medievales. La carencia de restos de espadas catalanas ha implicado que el estudio tipológico de las mismas se haya basado única y exclusivamente en su representación plástica, en la idea de que es éste el único medio posible de conocimiento ${ }^{9}$. Así, pues, la iconografía constituye la fuente primordial de este estudio. A no dudar, ello implicará la exclusión de datos fundamentales en el análisis de la espada, pues se deberá prescindir de intentar establecer, por ejemplo, las dimensiones de las mismas. De otro lado, se observarán incertidumbres en el análisis tipológico, dado que en algunos detalles la iconografía no resulta excesivamente explícita. Es necesario tener presente de forma constante el medio iconográfico en que se realiza el trabajo, y con ello nos referimos a que las formas de las espadas variarán considerablemente, ya que se encuentran en pintura, escultura, miniatura, sellos

5 Esta hipótesis la expuso K. BosL, Grundlagen der modernen Gesellschaft im Miltelalier, Stuttgart, A. Hiersemann, 1972, pág. 133.

6 Esta tarea constituirá el tema de mí tesis doctoral sobre el armamento catalán de los siglos XI al xin.

7 Entre ellos cabe citar el importantísimo estudio y la visión de conjunto de la espada medieval de A. Brunn De Hoffmeyer, Middelalderens tveaeggede svaerd, vol. I y II, Copenhague, 1954 (sumario en inglés); asimismo: Introduction to the bistory of the European Sword, en «Gladius», tomo I, Kalundborg, 1961, pp. 3071, y From medieval sword to Renaissance rapier, en «Gladius», tomo II, Instituto de Estudios sobre Armas Antiguas, Madrid, 1963, pp. 5-68.

8 Cf. A. Bruhn, Arms and armour in Spain. A short survey, vol. I, Madrid, Instituto de Estudios sobre Armas Antiguas, C. S. I. C., 1972. También E. OAKEsHOTT, The archaeology of weapons. Arms and armour from Prebistory to the age of chivalry, Lutherworth Press, London, 1963.

9 Tan sólo existen algunas piezas de la Armería Estruch, cuya procedencia podría ser catalana, cf. García Llansó, Armas y armaduras, Barcelona, 1895. 
o monedas; siendo éstas, además, las cinco fuentes iconográficas utilizadas en este estudio.

La pintura románica, ya sea mural o sobre tabla, se caracteriza estilísticamente por una bidimensionalidad y una carencia de perspectiva. Las espadas representadas pictóricamente asumirán una forma plana, impidiendo con frecuencia un análisis preciso del pomo. En definitiva, no resultará posible distinguir si el pomo es esférico o discoidal plano. Para solventar los problemas que ofrece la pintura románica en el reconocimiento de los distintos tipos de espadas se tuvo que recurrir a la escultura. La obra escultórica (en especial los capiteles) solventa desde el primer momento la bidimensionalidad de la pintura. El relieve de la escultura ha permitido precisar algunos aspectos de la espada románica; por ejemplo, el carácter plano o esférico del pomo. La espada aparece aquí exenta de su medio iconográfico, siendo posible estudiarla con mayor detalle. De otro lado, las dificultades que ofrecen los capiteles residen en la tosquedad con que, en su mayoría, están ejecutados, con un estilo que, a menudo, exagera el grosor y las dimensiones. No hay que olvidar tampoco el estado de conservación, que hace que algunas espadas aparezcan mutiladas. Asimismo ha de tenerse ell cuenta que las escenas guerreras con representaciones de espadas no resultan demasiado frecuentes en la obra escultórica, que tiende más bien a la representación ornamental y a la profusión de figuraciones monstruosas. La escultura ha sido tratada en este estudio como una fuente iconográfica secundaria, puesto que su misión ha consistido tan sólo en apuntalar los tipos de espadas establecidos en la pintura, así como para solventar aquellos problemas que ofrecía la pintura. Tanto la pintura como la escultura románicas catalanas aparecen en el siglo XII, extendiéndose plenamente durante todo el siglo XIII. La única obra plástica con representaciones de armas que Cataluña conserva del siglo XI se debe a las ilustraciones de las Biblias de Roda y de Ripoll. Las magníficas Biblias, pertenecientes a la segunda mitad del siglo XI, constituyen un documento de una riqueza inusitada. Así, pues, las Biblias se incluyeron en el estudio, aunque no sin ciertas reservas, debido a los problemas que giran en torno a su procedencia y a su cronología precisa ${ }^{10}$.

10 Los paleógrafos catalanes abogan por la procedencia catalana de las Biblias. Entre los más destacados figuran P. BoHígas y M. Mundo. Este último considera que la Biblia denominada durante mucho tiempo «de Farfa» tenía su origen en el monasterio de Ripoll, cf. P. BoHígas, La ilustración y la decoración del libro manuscrito en Cataluña (período románico), Asociación de Bibliófilos de Barcelona, MCMLX. Al mismo tiempo, P. Bonnassié, La Catalogne du milieu du $X^{e}$ à la fin du XI siècle. Croissance el mutations d'une société, Association des Publications de l'Université de Toulouse-le Mirail, 1976, utilizó las Biblias como fuente 
El estudio de las espadas que aparecen en las Biblias advirtió acerca de la escrupulosidad en el detalle con que están realizadas las espadas en los manuscritos. Estos se ofrecieron como una fuente idónea para perfilar con una mayor precisión los tipos determinados a través de la pintura. De cualquier forma, las miniaturas han constituido una fuente de segundo orden, en primer lugar porque no son muchos los manuscritos catalanes que presenten representacioncs de espadas, y en segundo lugar porque cuando aparecen espadas éstas se encuentran, por lo general, en ilustraciones subordinadas a un texto y no ofrecen un conjunto coherente de representaciones. Sin embargo, no pareció lícito desperdiciar aquellos ejemplos de espadas aparecidos de forma ocasional en los manuscritos; estos ejemplos han resultado muy valiosos para el desarrollo sistemático de esta investigación, pues han permitido observar los tipos de espadas con una nitidez que, a menudo, no resulta posible en el análisis de la pintura mural por el precario estado de conservación en que ésta se encuentra a menudo. De otro lado, es indudable que las líneas que delimitan las formas de las espadas resultan mucho más precisas en la miniatura que en la pintura. Al mismo tiempo, aquellos detalles que escapan de la percepción de la pintura mural pueden apreciarse en la miniatura, ya que ésta se caracteriza, ante todo, por un marcado perfeccionismo y rigor en las formas. La intensidad de la línea que delimita todo elemento representado en miniatura solventa la imprecisión de algunos detalles que en la pintura se confunden a veces dentro de una gama cromática extendida por todo el fresco. De esta forma, las ilustraciones de los manuscritos han permitido asentar y establecer de modo riguroso aquellos tipos, a menudo un tanto inciertos, constatados en la pintura.

Cualquier estudio que trate la pintura o escultura románicas deberá enfrentarse siempre con un grave problema: la cronología. La Historia del Arte se ha visto incapacitada para fechar con exactitud las piezas del arte románico. No voy a intentar dilucidar aquí en dónde reside exactamente dicha dificultad, pero lo cierto es que no se puede contar con una fecha más precisa a la oscilante en un siglo de duración. Dentro de una perspectiva histórica, la cronología escrupulosa es un dato del que no se puede prescindir, porque es precisamente ella quien conforma la historia. Sin una cronología precisa la historia se vuelve difusa, y eso es obvio. La obsesión por poder ofrecer una precisión cronológica ma-

documental para su estudio (véase, por ejemplo, pág. 580). A pesar de todo, las miniaturas de las Biblias presentan a la hora de su interpretación serias dificultades, que hacen dudar tanto de la procedencia atribuida como de la cronología impuesta. 
yor nos ha conducido a buscar una fuente iconográfica que concediera fechas más seguras a las de la pintura y escultura. De esta forma tuvimos que recurrir a la sigilografía, en la idea de que ésta era la única fuente precisa en lo que a cronología se refiere. En los sellos la incertidumbre cronológica no sobrepasa los diez años de duración, ofreciendo, la mayoría de las veces, una única fecha. Se han incluido tanto los sellos procedentes de la casa real como los procedentes de las distintas casas nobiliarias. A pesar de la enorme cantidad de sellos existentes de las casas nobiliarias es necesario destacar que, a diferencia de la casa real, son pocos los que presentan espadas. Con una frecuencia mucho mayor encontramos los escudos correspondientes a las distintas casas, así como representaciones de castillos, entre algunas ilustraciones de otro tipo. El estudio de los sellos ha permitido fijar fechas de forma precisa de aquellos tipos de espadas determinados en la atenta observación de las tres fuentes iconográficas que acabamos de analizar. Sin embargo, ha de tenerse presente la enorme dificultad que ofrece el examen de la espada en el sello. Muchos de los sellos se encuentran en un estado de conservación muy precario, y el reducido tamaño de los mismos impide observar con claridad sus representaciones. Los sellos no podrían utilizarse nunca como documento único para establecer tipos de espadas, sino que deben emplearse como un enriquecimiento de las fuentes iconográficas ya citadas y, en especial, como el único medio para establecer cronologías definitivas. Es en este sentido por lo que se ha incluido en este estudio la fuente documental de los sellos, que, por otra parte, incita a otros campos de análisis interesantísimos encaminados más a desvelar el significado profundo de la espada feudal que su propia tipología.

La numismática constituye una fuente de documentación interesantísima para una variedad muy amplia de temas y también puede resultar útil en el estudio de la espada. Existen monedas catalanas con representaciones de espadas en los siglos XI al XIII, pero su reducido tamaño impide un análisis tipológico detallado. De cualquier modo, es interesante observar la evolución del tratamiento de la espada en la moneda a lo largo de toda la Edad Media ". Así, pues, aun cuando esta fuente no resulte excesivamente apta para el estudio tipológico de la espada, nos ha parecido que es digna de tenerse en cuenta.

En suma, la pintura ha sido considerada como el documento primordial. Las dudas de orden tipológico y cronológico incitaron a la búsqueda de nuevas fuentes, siendo añadidas la escultura, miniatura, sellos

11 Para ello véase J. E. Cirlot, La espada en la moneda medicval, en «Gladius», tomo VIII, 1969, pp. 17-22. 
y monedas. De esta forma creo poder ofrecer una visión de conjunto de los distintos modos de representación de la espada, según los diferentes medios iconográficos en que ésta fue tratada. Asimismo, los tipos establecidos adquirirán una solidez y consistencia mayor, dado que se fundamentarán en fuentes diversas. De otro lado, al utilizar todas las fuentes iconográficas del arte románico habré analizado, estrictamente hablando, la representación de la espada en la época feudal.

Si el arte es un documento que la historia no está en condiciones de despreciar, la literatura constituye una fuente preciosísima, muy digna a tener en cuenta por la historiografía. El erudito alemán W. Giese analizó con gran precisión la terminología referente al armamento utilizada en las fuentes literarias. Martín de Riquer, por su parte, ofreció una visión de conjunto del armamento catalán desde la época condal hasta el siglo xv. Para ello expurgó a conciencia toda la literatura catalana de la época, basándose también en algunos ejemplos iconográfi$\cos ^{12}$. La literatura catalana informa con todo detalle acerca de las distintas piezas de armamento, deteniéndose a menudo en abundantes explicaciones, incluso definiendo, de forma explícita, algunos de los elementos fundamentales en el «arnès del cavaller». Sin embargo, en nuestro caso las fuentes literarias no resultan demasiado elocuentes. Los siglos XI y XII carecen de literatura que, de alguna forma, se refiera al armamento. Como ya señala el propio $M$. de Riquer, la carencia de canciones de gestas catalanas reduce considerablemente la información que pudiéramos adquirir acerca del armamento de la época ${ }^{13}$. $\mathrm{Al}$ mismo tiempo es necesario destacar que la literatura ofrece detalladas descripciones del armamento defensivo, pero nunca se detiene en analizar la espada. Las dos únicas obras que entran dentro de nuestra cronología propuesta - Libre de l'orde de cavalleria, de R. Llull, y Libre dels feyts, de Jaime I- nada especial aportan acerca de la morfología de la espada.

12 Para el estudio del armamento a través de la literatura, véase W. Giese, Waffen nacb der katalanischen Cbroniken des XIII Jabrbunderts, en «Volkstum und Kultur der Romanen», I, 1928, pp. 140-182. Del mismo autor: Waffen nacb der spanischen Literatur des XII und XIII Jabrbunderts, en «Mitteilungen und Abhandlungen aus der Gebiet der romanischen Philologie», Hamburg, 1925. Id., Waften nach der provenzalischen Epen und Chroniken des XII und XIII Jabrbunderts, en «Zeitschrift für romanische Philologie», LII, 1932. Por su parte, M. DE Riquer, L'arnès del cavaller. Armes i armadures catalanes medievales, Barcelona, Ariel, 1969.

13 Cf. M. DE Riquer, op. cit., pág. 17. Ello no indica que en Cataluña no hubieran existido canciones de gesta, desaparecidas en la actualidad, debido al carácter oral de su divulgación: cf. M. DE RIQuer, Història de la literatura catalana, Barcelona, Ariel, 1964, pág. 391. 
Así, pues, esta investigación no ha tratado las fuentes literarias ni se ha basado en ellas. La elaboración de una tipología de la espada catalana sólo podrá realizarse mediante la reunión de todas las fuentes iconográficas posibles, debido, por un lado, a la inexistencia de restos arqueológicos; y por otro, a la esterilidad literaria en lo que respecta al tema de la espada.

\section{Tipología de la espada catalana dE los Siglos Xi $\Lambda \mathrm{L}$ XiI}

El estudio de la espada a través de la iconografía requiere una reconstrucción de la misma en el sentido estricto del término. El estado de conservación es factor determinante en la reelaboración de las líneas que delimitan las espadas, dado que, en muchas ocasiones, aparecen fragmentadas o diluidas en el fondo pictórico. De otro lado, la representación distrae en su conjunto al observador, conduciéndole a centros de atención insospechados para él, ya sea debido a una atracción por de. terminados colores o formas específicas. Cualquier espectador frente a una obra artística deja guiarse de forma inconsciente por elementos que atraen y seducen su atención. De este modo, la representación específica que aquí nos interesa, la espada, aparece inmersa en una composición de elementos que, indudablemente, podrían hacer desviar la mirada hacia puntos distintos, confundir la representación de la espada en la configuración múltiple e incluso ocultarla. Por ello pareció absolutamente necesario extraer la representación de la espada del conjunto iconográfico en donde se encontraba, dado que el análisis preciso de la misma sólo podría realizarse en su única y exacta observación. Por lo mismo, este estudio se ha basado en los dibujos extraídos por procedimientos mecánicos de las fotografías.

El estudio formal de la espada exige una elaboración tipológica. La configuración de una tipología de la espada no resulta en modo alguno fácil y, al mismo tiempo, puede conducir a graves errores. Son éstos los errores propios de todo intento de elaboración de «tipos ideales» (Idealtypen), que, a menudo, distorsionan la realidad por su carácter estático y cerrado. La labor histórica debe rechazar constantemente aquellos esquemas que, por su simplismo y reduccionismo, no correspondan a la realidad. El violento rechazo por parte de la historiografía actual al estructuralismo antropológico tiene su origen en estas causas. Pero, al mismo tiempo, el historiador reconoce que es necesario operar sobre «estructuras», rectificando muchos de los aspectos que el estructuralismo tradicional les concedió. En este sentido, pretendemos establecer una tipología dinámica y abierta a cualquier modificación o rees- 
tructuración. Es necesario huir de la sumisión que, a menudo, impone la tipología, en la consideración de que ésta no es más que un principio de clasificación. Desde esta perspectiva, la tipología no deberá nunca imponerse sobre la lógica y la congruencia temático-formal. Pero sin la elaboración tipológica el análisis de la espada se concibe confuso e incluso imposible. Agrupar todas las formas de espadas en los distintos tipos constituye una tarea que no resulta posible dejar de lado. Para ello, los estudios realizados por los distintos especialistas europeos han resultado imprescindibles. En la elaboración tipológica hemos seguido un método idéntico al utilizado por los estudiosos del armamento y, en especial, al de Ada Bruhn de Hoffmeyer ${ }^{14}$. Todas las espadas europeas han sido sistematizadas en tipos aceptados por todos los especialistas. Sin embargo, existen criterios discrepantes en lo que se refiere a la elaboración tipológica. Dichas discrepancias se deben a los distintos criterios, que conceden mayor o menor importancia a los distintos elementos de la espada, en especial la hoja y la empuñadura. E. Oakeshott opina que toda tipología de la espada debe fundamentarse también en el análisis de la hoja y no sólo de la empuñadura, tal y como pensaron E. Behmer y J. Petersen ${ }^{15}$. Por el contrario, Ada Bruhn considera que la hoja es un elemento secundario a la hora de establecer una tipología, debido a que las hojas de las espadas se producían en masa, mientras que la empuñadura constituía un trabajo individual. Al mismo tiempo, advierte que no se debe desdeñar ningún elemento de la espada para establecer una cronología. Así, deberá tenerse en cuenta las hojas y las empuñaduras, sus proporciones, el material, la técnica, las inscripciones, en la concepción de que la espada es un conjunto que debe ser observado como tal. Pero incide en el hecho de que la empuñadura de la espada constituye la parte fundamental para la elaboración tipológica, y considera el pomo como el elemento primario y el arriaz como elemento secundario ${ }^{16}$. Los criterios de Ada Bruhn nos parecen muy acertados, $\mathrm{y}$, al mismo tiempo, son los únicos que aquí pueden adoptarse. Si el estudio de las hojas de las espadas no resulta muy elocuente en las piezas arqueológicas, en la iconografía resulta imposible. Es

14 No he podido consultar las tipologías establecidas por E. BEHMER y J. PETERSEN. De cualquier modo, éstas son recogidas por E. OnKeshotT, The archaeology, cit., y en especial A. Bruhn, Middelalderens, cit.

15 Cf. E. OAKESHO'T, op. cit., pág. 203: «The sword typologies worked out by Behmer and Petersen were based mainly upon styles of hilt, and hilt and scabbard ornamentation, taking little or no account of the shapes of blades, but when we consider the sword types of the later Middle Ages we have to reckon many differing blades forms which have an all-important bearing on classification».

16 Cf. A. Bruhn, Middelalderens, cit., pág. 183. 
cierto que, en ocasiones, la dimensión de la hoja constituye un dato muy revelador, pues su anchura y longitud variaban según las distintas épocas ${ }^{17}$. Sin embargo, la imposibilidad de inclusión de este dato obliga a rechazar la hoja como elemento válido para la tipología. Si en algunas ocasiones nos referimos a ella es tan sólo a modo indicativo, pues el criterio tipológico que utilizaremos será el análisis de la empuñadura. A diferencia de Ada Bruhn, concederemos la misma importancia al arriaz que al pomo, dada la interesante variedad que ofrece. De esta forma, los tipos variarán según el pomo o arriaz de modo indiferente y los subtipos serán las variaciones sensibles de los tipos, ya sea en el pomo o en el arriaz.

No hay que olvidar que nuestra tipología se basa tan sólo en espadas extraídas de la iconografía. A menudo advierten los especialistas de armas que las piezas estudiadas deben ser confrontadas con ejemplos en la iconografía ${ }^{18}$. Nuestro criterio será por necesidad a la inversa. Las espadas representadas en la iconografía catalana serán confrontadas, a falta de restos arqueológicos propios, con las espadas que se encuentran en los diversos museos europeos y, al mismo tiempo, con algunas muestras de la iconografía europea. De esta forma logramos dos propósitos: por un lado, apuntalamos y constatamos con mayor precisión los tipos establecidos por nosotros, y por otro, comparamos implícitamente la espada catalana con la espada europea. Una de las causas principales e inmediatas que motivan este estudio consiste en la posibilidad de responder a la pregunta acerca de cómo era la espada catalana en la época feudal. En esa misma pregunta se incluye la cuestión de si la espada catalana se diferenciaba o asemejaba a la europea. El estudio tipológico de la espada catalana deberá responder a estas cuestiones.

\section{TIPO I: POMO EN «FORMA DE NUEZ», ARRIAZ RECTO}

Brazil-nut pommel, straight quillon

La característica principal de las espadas agrupadas bajo el tipo I consiste en presentar un pomo en una forma que podría denominarse «de nuez» y un arriaz recto (Fig. 1). Dicho tipo I corresponde al tipo I

17 CF. H. SEITZ, Blankwaffen. Gescbicbte und Typenentwicklung im europäischen Kulcurbereich. Von der prähistorischen Zeit bis zum Ende des 16. Jabrbunderts, Klinkhardt \& Biermann, Braunschweig, 1965, pág. 145.

18 Cf. E. OAKeshotT, The arcbaeology, cit., pág. 202: «In describing and illustrating examples of each type I shall use wherever possible one of these 'fixed point' swords together with comparable examples in sculpture and painting». 
de la tipología trazada por E. Oakeshott, que según su autor se extiende desde finales del siglo $\mathrm{x}$ hasta el primer cuarto del siglo xiII ${ }^{19}$. Por su parte, H. Seitz retrasa algunos años la cronología establecida por Oakeshott y se extiende hasta $1275^{20}$. Ada Bruhn introduce este tipo

Fıg. 1,-Tipo I

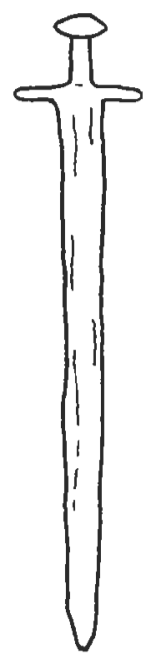

dentro de un grupo II ${ }^{21}$ y opina que este tipo predomina desde el 1100 hasta el 1250. Ninguno de los tres autores duda acerca de que este tipo I procede de una forma anterior que se distinguía por presentar un pomo semiesférico. La espada de pomo semiesférico y arriaz recto constituye un tipo de transición y perteneció al último período vikingo ${ }^{22}$. A no dudar, es precisamente el «tipo de transición» quien generará la espada románica ${ }^{23}$. De inmediato puede

19 Cf. E. Oakeshott, op. cit., pág. 204.

${ }^{20}$ Corresponde al tipo de pomo denominado por H. SEITz (Blankwaffen, cit., pág. 133) Paranussförmiger (Abd. 75, 10-12).

21 Cf. A. BRuHn, Middelalderens, cit., pág. 186.

22 Ibidem, pág. 185: «Swords of the transitional period», que proceden del grupo I.

${ }_{23}$ Debe hacerse notar aquí que el término románico ofrece ciertas dificultades dentro de la terminología estrictamente histórica. Se trata de un concepto extraído de la historia del arte y aquí lo utilizaré en la convicción de que la espada constituye un objeto artístico al igual que cualquier otro. De cualquier forma es éste un término utilizado por los especialistas. Véase A. BrunN, Middelalderens, cit., página 187: «Romanesque sword». 


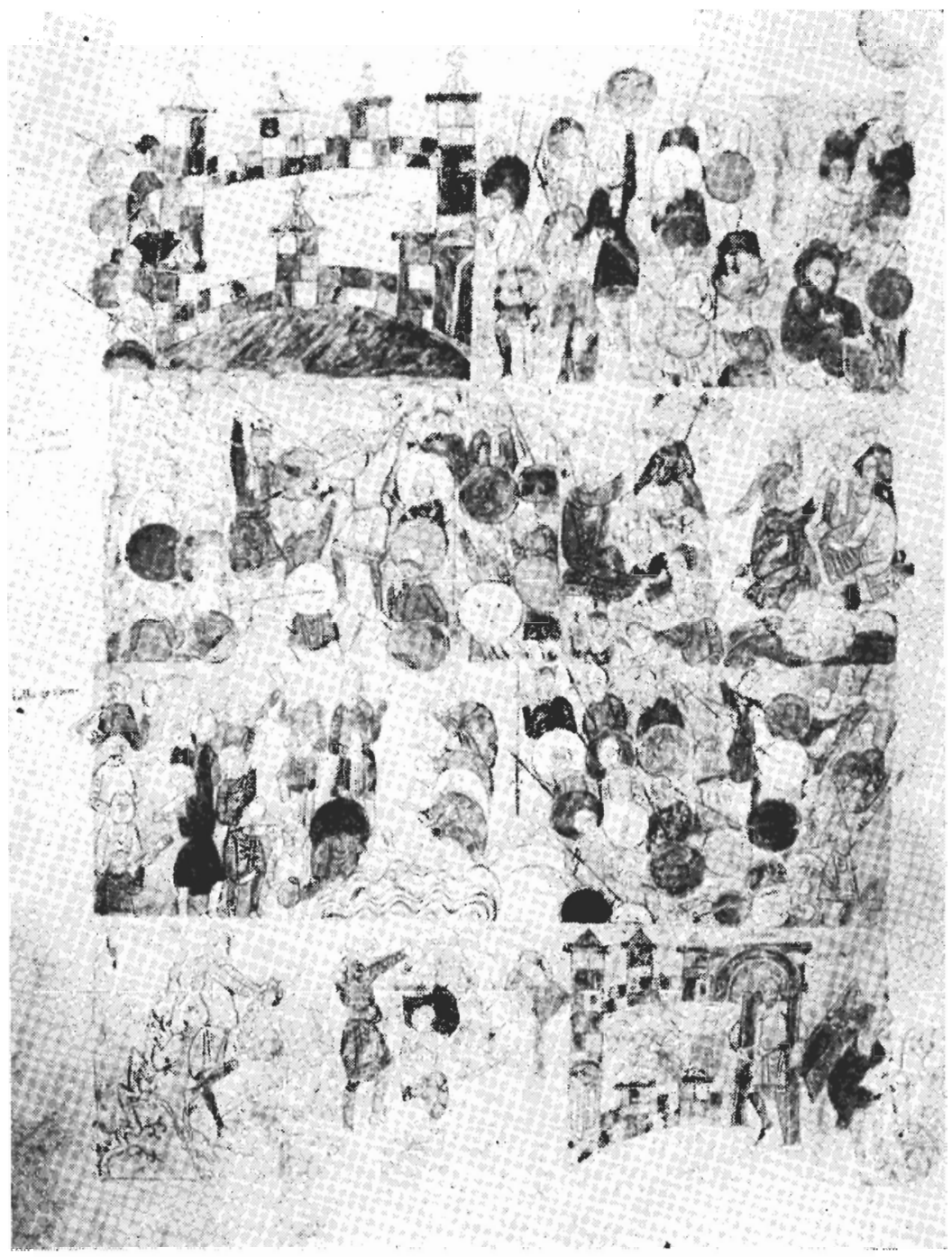

Fото I.-Bibiia de Ripoll, folio $82 \mathrm{v}^{\circ}$ (s. x1). Espada tipo I (superior derecha) 
advertirse la dificultad que presenta el tipo I en la iconografía, dado que en muchas ocasiones no resulta posible discernir si el pomo es semiesférico o si bien presenta forma de nuez.

En el folio $82 \mathrm{v}^{\circ}$ de la Biblia de Ripoll se observa un guerrero en la parte superior derecha que lleva en el cinto una espada de hoja muy larga, un arriaz algo inclinado y un pomo que, indudablemente, no presenta una forma semiesférica perfecta (Foto I). Cómoda y sencilla solución sería la de achacarle al artista una supuesta imperfección en la ejecución del pomo. Desechamos ya de raíz esta explicación, pues la habilidad del trazo que demuestra en el resto de la representación impide la posibilidad de un descuido, precisamente en un elemento de gran importancia. Así, pues, la forma algo achatada del pomo por su parte superior y el ligero abombamiento por la parte inferior conducen a considerar esta espada como un claro tipo I ${ }^{24}$.

En un extraordinario capitel de la catedral de Tarragona (principios del siglo XIII) se esculpió una representación perfectamente simétrica

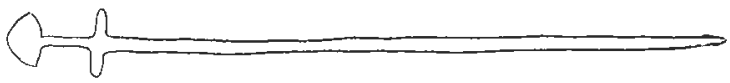

de dos guerreros luchando contra dos monstruos, escena que se encuentra toda ella inmersa dentro de un ritmo de ornamentación profusa. El eje de simetría está marcado por dos espadas idénticas. Ambas espadas presentan la línea inferior que dibuja el pomo inclinada y bombeada hacia arriba (Foto II). La rectitud del arriaz junto con la forma de nuez del pomo nos inducen a incluirlo, sin ningún género de dudas, dentro del tipo $\mathrm{I}^{25}$.

No hay que ocultar que este tipo I no se encuentra excesivamente fundamentado. Ello se debe, en parte, a que este estudio se basa principalmente en la pintura y, precisamente, la única muestra pictórica que disponemos del tipo I, Santa María de Tarrasa, no resulta muy explícita. El hecho de que no aparezca en un número mayor de pinturas

${ }^{24}$ Muy similares son dos espadas del folio $6 \mathrm{v}^{0}$ de la Biblia de Ripoll. Un ejemplo pictórico es la espada que sostiene el caballero situado a la izquierda de Santo Tomás de Canterbury degollado, en el ábside lateral de Santa María de Tarrasa (segunda mitad del siglo xil).

${ }_{25}$ De este mismo tipo se puede considerar la espada de un relieve procedentc del monasterio de Poblet (Metr. Mus.), aunque el pomo sea casi triangular (s. XIII). Véase también el scllo de Alfonso II, de 1193, en F. SAGARra, Sigillografia catalana. Inventari, descripció $i$ estudi dels segells de Catalunya, Barcelona, 1916, t. II, número 3. 


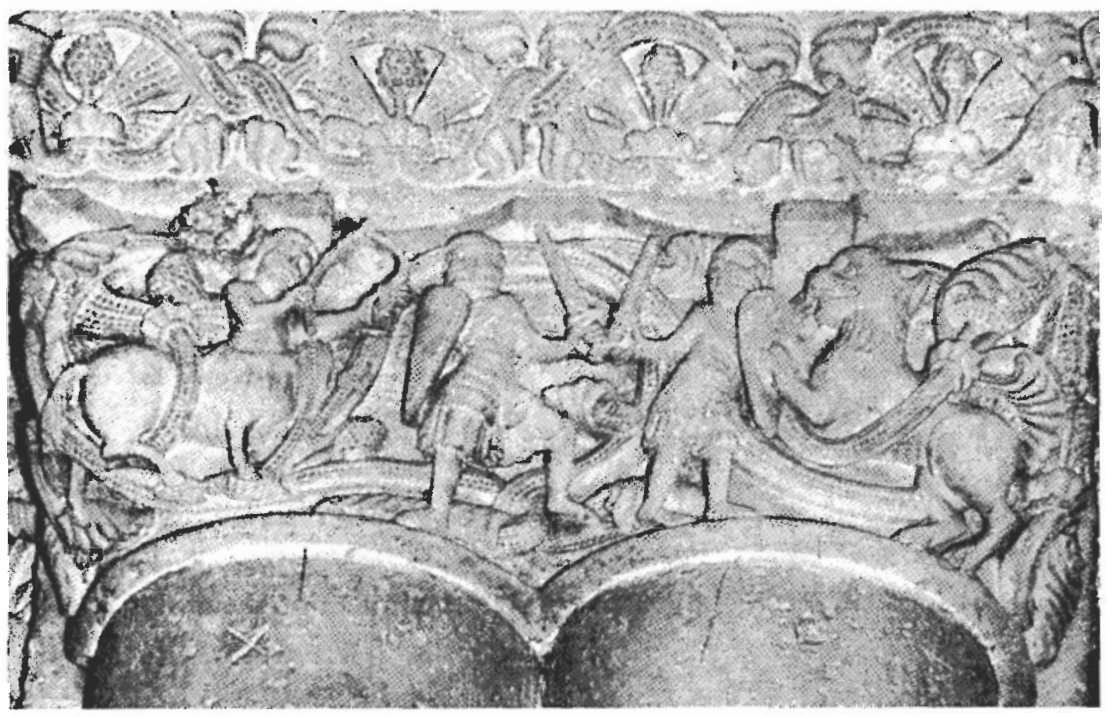

Fo'to II.-Capiteles del claustro de la catedral de Tarragona, s. X111, zona central: dos espadas tipo I

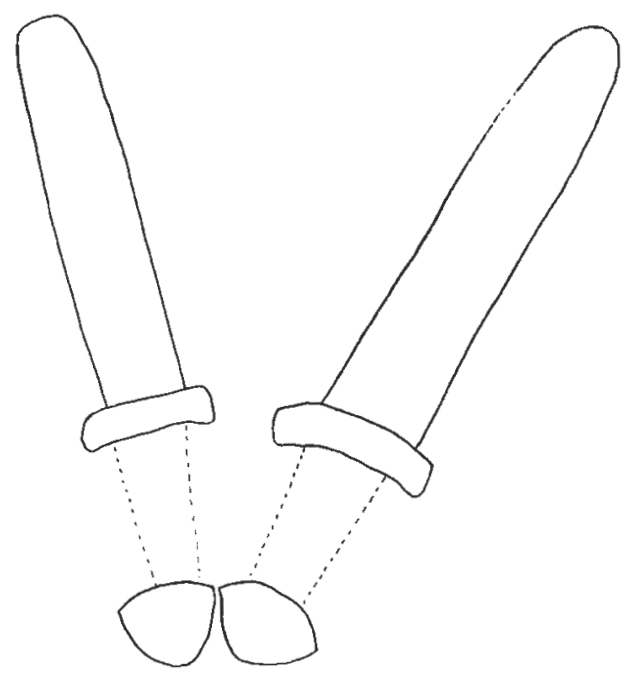


podría deberse a que se trata de un tipo característico de los siglos XI y XII, época de la que Cataluña conserva escasos ejemplos pictóricos. De otro lado, si bien este tipo perduró hasta el siglo xIII, como lo demuestra la escultura, también es cierto que ya no era un tipo muy usual y propio de la época. Sin embargo, no resultaba posible prescindir de aquellos ejemplos que cuentan con numerosas referencias en algunos museos de Europa e incluso en dos claros ejemplos de la Armería Estruch ${ }^{26}$. Una de las espadas más famosas que existen de este tipo es la denominada espada de San Mauricio, que se encuentra en la Tesorería Imperial de Viena ${ }^{27}$. La espada de la Foto I se asemeja extraordinariamente a esta magnífica pieza, fechada hacia 1200. Una espada que actualmente se encuentra en el Museo Histórico de Berna (1100-1200) presenta un indudable parecido con la de la Foto II ${ }^{28}$. Otra representante de nuestro tipo I es la magnífica pieza de la. Wallace Collection, fechada entre 1150 y $1280^{29}$. Numerosas piezas de este tipo ofrecen el Landesmuseum de Zürich y el museo de Copenhague, entre otros ${ }^{30}$.

Aun cuando la representación de la espada tipo I no sea muy abundante en la iconografía, resulta crucial para el entendimiento de la evolución de la espada en Cataluña. El siglo xi catalán arranca, como lo demuestran las Biblias de Roda y de Ripoll con un tipo específicamente europeo, un tipo que procede de la espada vikinga y que dará lugar, en una evolución formal, a la espada típicamente románica. Así, pues, y atendiendo a las fuentes iconográficas utilizadas para el establecimiento del tipo I, deberemos considerar que dicho tipo aparece en Cataluña hacia la segunda mitad del siglo XI, utilizándose en el siglo XII, sin ningún género de dudas en 1193 _-tal y como lo demuestra el sello de Alfonso II-, y desaparece durante el siglo xIII. Si bien son escasos los ejemplos ciertos que argumenta el tipo I, ellos constituyen, a pesar de todo, la prueba indudable de que en Cataluña se utilizaron espadas análogas a la de San Mauricio: la espada con pomo en forma de nuez y arriaz recto. $Y$ se emplearon dentro de la cronología usual, establecida por los especialistas europeos, para nuestro tipo I: desde 1070 hasta 1250 .

26 Cf. García Llansó, op. cit., pág. 31.

27 Cf. E. OAKeshotT, op. cit., lám. 8 (a).

28 Cf. H. SeITZ, op. cit., pág. 139, Abd. 81.

29 Cf. J. Mans, Wallace Collection Calalogues. European Arms and Armour, London, 1962, A 457 Sword, plate 105.

30 Cf. A. BRUHN, Middelalderens, cit., tomo II, PI. IV-VI. 


\section{Tipo II: Pomo discoidal plano o ESfÉrico, arriaz Recto}

Flat disc-pommel or spberical pommel and straight quillon

La inclusión en un solo tipo de dos formas tan distintas como pueden ser un pomo discoidal plano o un pomo esférico tiene su origen en las fuentes utilizadas. Esta disyunción no tendría lugar si trabajáramos con piezas arqueológicas. Sin embargo, y como ya hemos advertido, no resulta posible distinguir en pintura el carácter plano o esférico del pomo. Así, pues, deberá tenerse presente que muchos de los ejemplos aquí introducidos podrán presentar tanto el pomo plano como esférico (Fig. 2). Nuestro tipo II no corresponde de forma exacta a

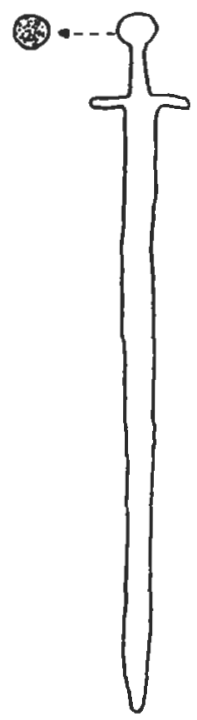

FIG. 2.-Tipo II

la tipología elaborada por los especialistas europeos. La causa de esta discrepancia se debe, sin duda alguna, a la disparidad de las fuentes. En cualquier caso, nuestro tipo II se adecúa al grupo IIIa establecido por Ada Bruhn, pero este último comprende tan sólo las espadas con pomo discoidal plano y arriaz recto. La autora introduce en el mismo grupo III, y como una variante, las espadas con pomos esféricos. Considera que ambos tipos aparecen alrededor del 1150 y perduran hasta el siglo XIII ${ }^{30}$. El tipo XI de E. Oakeshott se aparta un tanto de nuestro tipo II, dado que el autor incluye dentro de este grupo las espadas

\section{4}


con pomos algo semejantes a los de en forma de nuez, junto con los discoidales planos. El tipo XI de Oakeshott se vulgariza, según su propio autor, desde 1120 hasta 1200. E. Oakeshott introduce las espadas con pomos esféricos dentro de un tipo XII, considerando que la cronología de este tipo es posterior a la del anterior, pues se extiende desde 1180 hasta $1320^{31}$. Por su parte, H. Seitz no introduce dentro de su tipología las espadas con pomos esféricos, apareciendo tan sólo las espadas con pomos discoidales planos (Scbeibenknauf). E1 autor remonta la aparición del pomo discoidal plano hasta la época vikinga,

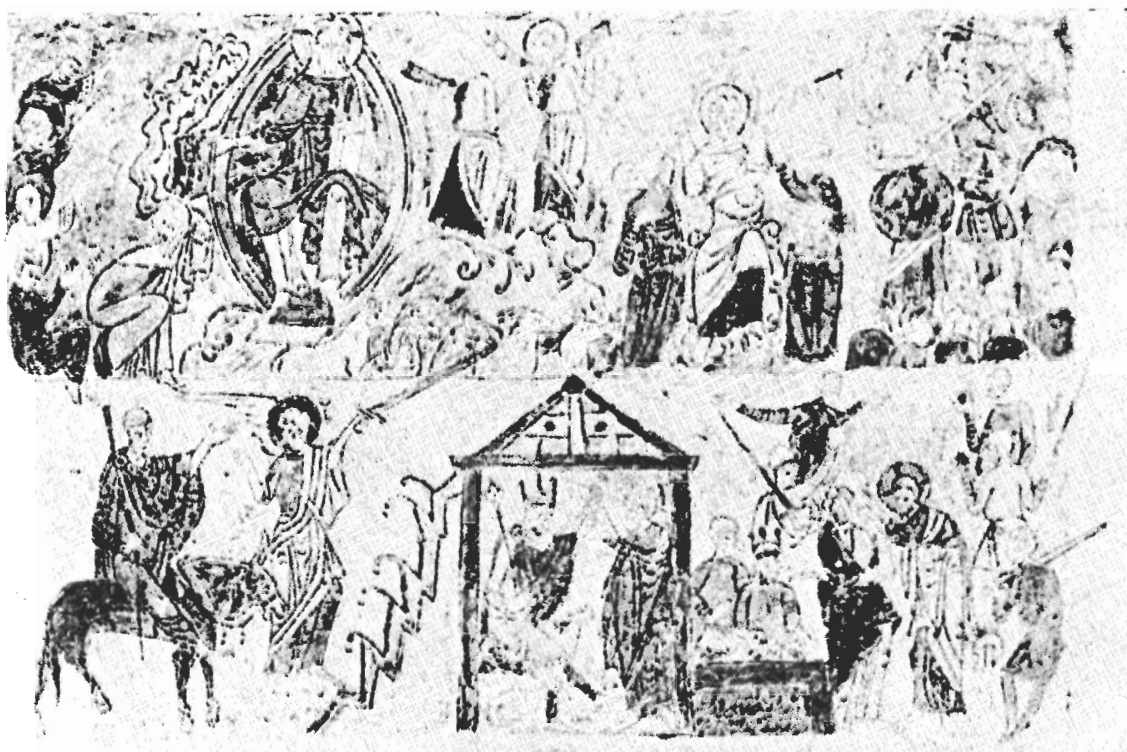

Fото III.-Biblia de Ripoll, f. 82, s, xi. Zona inferior izquierda: una espada tipo II.

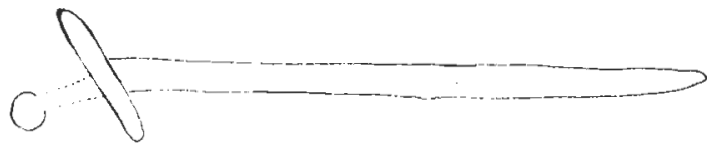

31 Véase E. ОлкеSнотт, op. cit., pág. 205 у 207. 


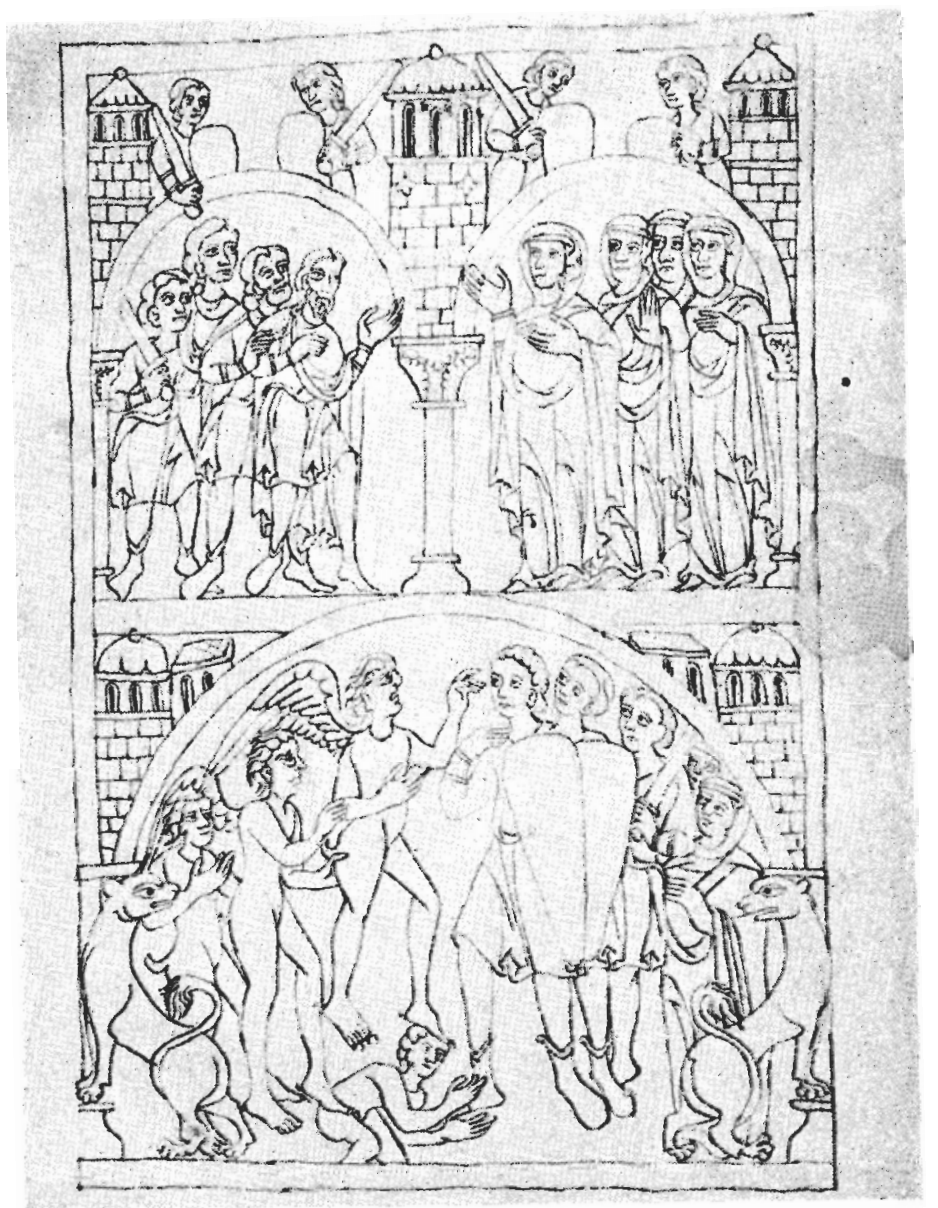

Foto IV.-De Civitate Dei, de San Agustín (Tortosa, catedral), f. 1 , s. XII. Espada tipo II

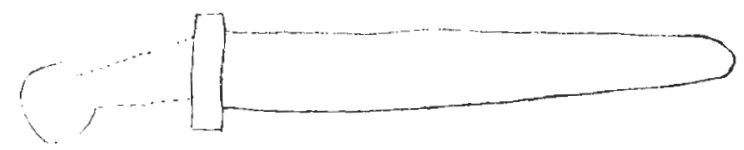


utilizándose ya hacia el año 1000 , si bien acepta que la plena extensión del tipo no tuvo lugar hasta el año 1100 , en plena edad románica ${ }^{32}$. Las espadas del tipo II solían llevar, con frecuencia, inscripciones tales como HOMO DEI ${ }^{33}$.

Una ilustración de la Biblia de Ripoll (folio 82), permite distinguir con claridad en la zona inferior izquierda, una espada sostenida también por un ángel. Tan sólo el trazo de las líneas conforman la espada, siendo posible adivinar la canaladura. El pomo, ya sea plano o esférico, se encuentra algo desplazado de la posición que le correspondería con respecto a la hoja (Foto III) ${ }^{34}$. Las cinco espadas que aparecen en el folio 1 del De Civitate Dei, de San Agustín (siglo xII), difieren un tanto de la anterior, pues aquí desaparece la acentuada estilización que caracteriza a la de la Biblia de Ripoll. Las cinco espadas son idénticas y presentan un pomo discoidal plano o esférico, un arriaz recto que no sobresale mucho de la hoja y una hoja lisa. La ausencia de sombras hace que todas estas espadas presenten una forma específicamente plana (Foto IV). Las tablas del Martirio de Santa Lucia (siglo xIII) ofrecen dos espadas muy semejantes. Una de ellas está colgada del cinto del caballero y presenta un pomo discoidal plano o esférico con la hoja introducida en la vaina (Foto V). Dos espadas del tipo II aparecen también en la zona inferior izquierda del Frontal de Durro, dedicado a San Quiricio y a Santa Julia (siglo XIII). Ambas espadas destacan por su color blanco del conjunto representativo (en rojo) y, en especial, de los dos guerreros, situados a ambos lados de Santa Julia, también vestidos de un rojo muy intenso. Dichas espadas tienen unos pomos planos o esféricos, unos arriaces relativamente anchos y las hojas con las puntas ligeramente redondeadas (Foto VI). Hay que destacar que la representación pictórica del tipo II resulta muy usual, apareciendo en los tres conjuntos de pintura mural laica de estilo románico más importantes que Cataluña conserva: en las escenas del castillo catalán (posiblemente de Urgellet) (siglo XIII), en la pintura mural del Palacio Real Mayor y en la Conquista de Mallorca por Jaime I de la calle Montcada (principios del siglo XIV) ${ }^{35}$.

32 Cf. H. Seitz, op. cit., pág. 133, Abd. 75 y pág. 147.

33 Cf. A. Bruhn, Middelalderens, cit., pág. 187. Véase también E. OAKeshotT, op. cit., pág. 250. A pesar del extraordinario interés que ofrecen las inscripciones de las espadas no resulta posible incluir aquí este tema dado que no hemos podido constatar ninguna inscripción en ninguna representación de espadas.

34 Muy similares las espadas que aparecen en los folios 95 (parte superior) y $82 \mathrm{v}^{\circ}$ (zona superior) de la misma Biblia.

35 Asimismo, la espada que empuña el rey David en la escena de «David y Goliat», de Santa María de Tabull (siglo xiI) y la espada que empuña el caballero de la pintura mural de la Balmesiana. Acerca de las pinturas de la calle Montcada, 


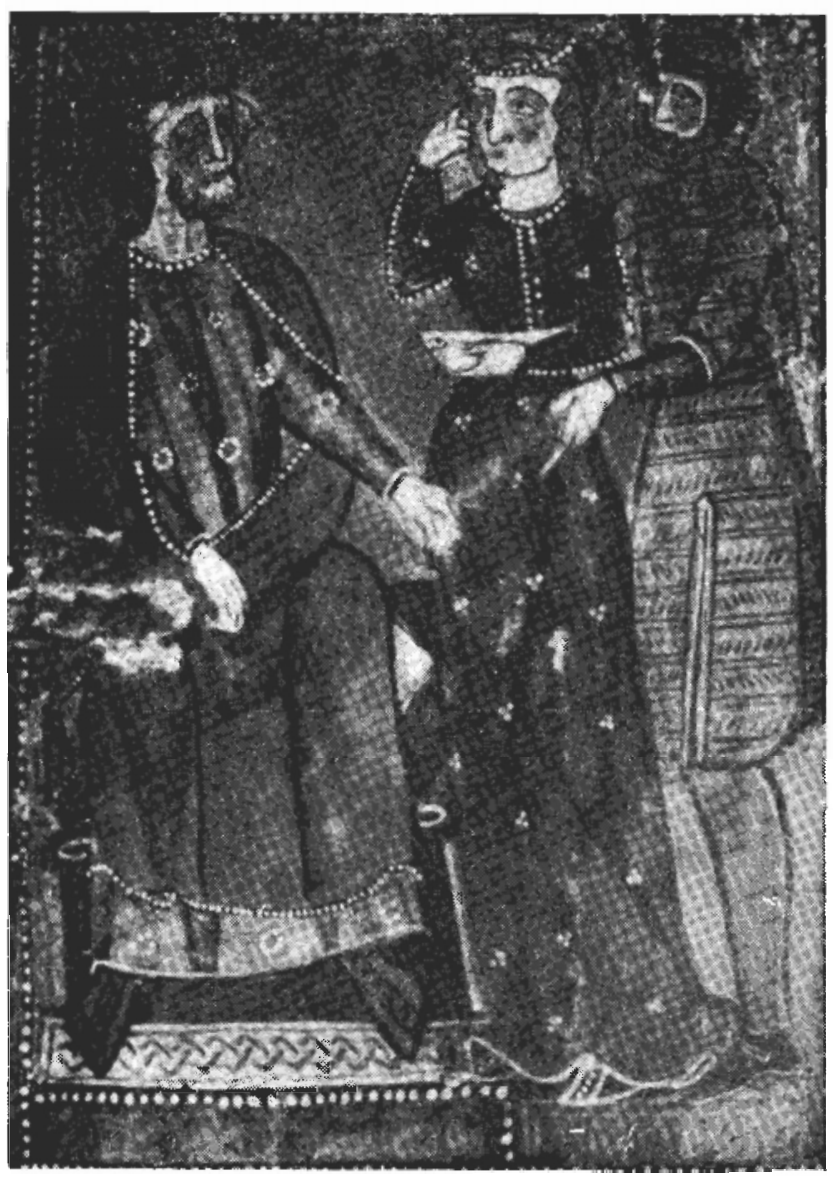

Foto V.-Martirio de Santa Lucía (Mur), Lérida, siglo xill, M. A. C., sala 32. Espada tipo II

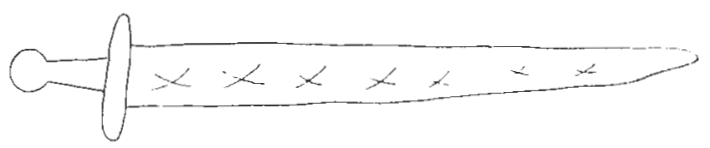




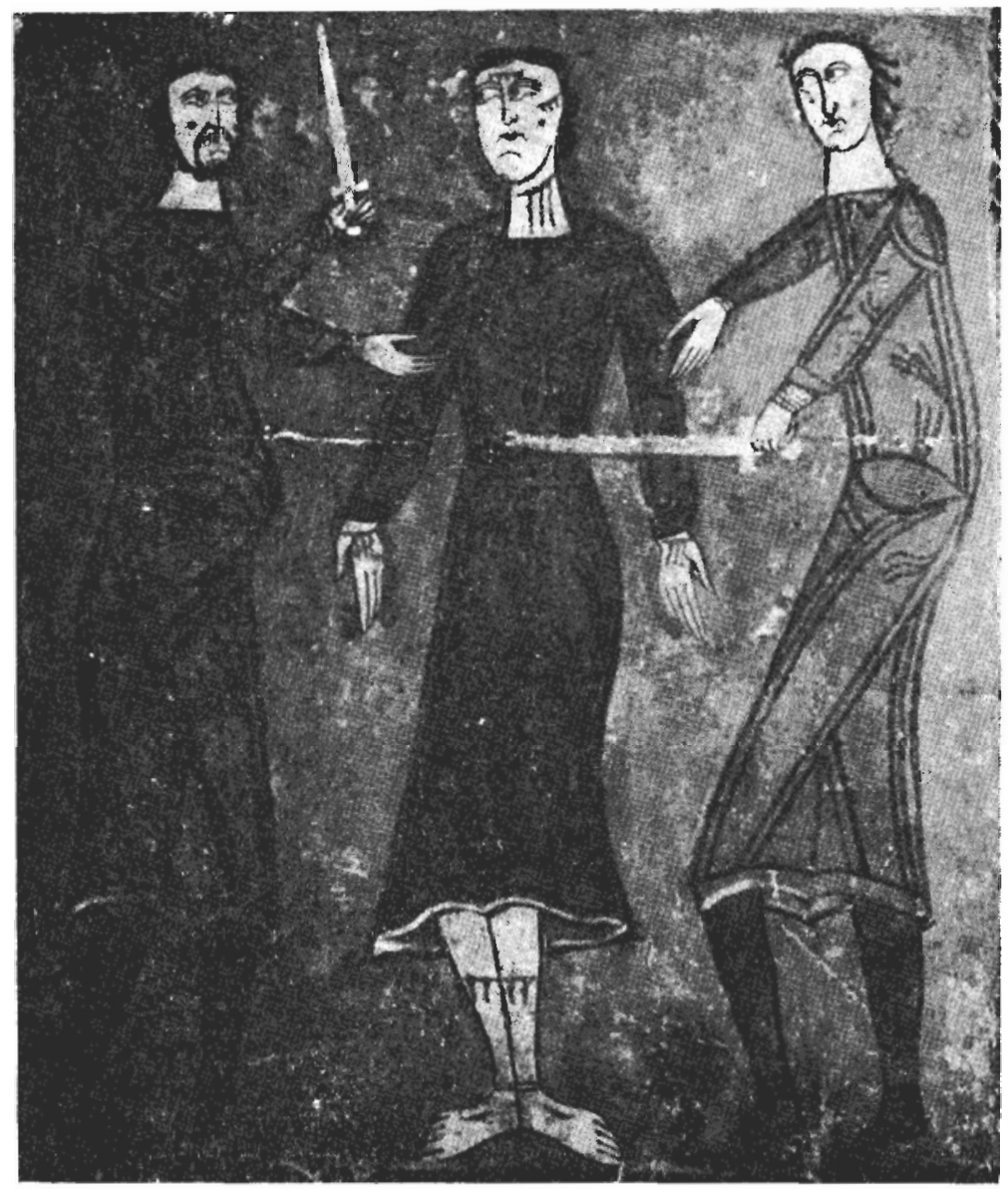

Foto VI.-Frontal de Durro, dedicado a San Quiricio y Santa Julia, s. xin, M. A. C., sala 5, zona inferior izquierda: espada tipo II 
Después de esta rápida descripción de las espadas representadas en miniatura y pintura, resulta ya posible advertir la problemática que ofrecen estas fuentes en la apreciación rigurosa de la espada tipo II. En este sentido, ni la miniatura ni la pintura pueden responder acerca del carácter plano o esférico del pomo. De inmediato se plantea la cuestión acerca de la existencia real en Cataluña de espadas con pomos esféricos. La cuestión puede plantearse también a la inversa y achacarle a la pintura una incapacidad técnica para representar pomos esféricos. El análisis de la espada esculpida es el único que puede resolver el problema. El relieve en la escultura permite determinar, de forma precisa, la esfericidad o el carácter plano del pomo.

En un capitel del claustro de la catedral vieja de Lérida están esculpidos dos caballeros que luchan con sus espadas, montados sobre dos animales monstruosos. La espada del guerrero izquierdo aparece con un pomo destrozado, pero la del guerrero de la derecha conserva perfectamente el pomo esférico (Foto VII) ${ }^{36}$. Y en otro capitel de la misma catedral nos encontramos con una espada cuyo pomo es circular y su grosor no excederá, con mucho, los dos centímetros. Se trata de una espada de pomo discoidal plano y arriaz recto (Foto VIII). Así, pues, la escultura ha constatado la existencia de espadas tanto con pomo esférico como discoidal plano. Sin embargo, parece que el número de espadas esculpidas con el pomo esférico es mucho mayor al de espadas con pomo discoidal plano. Parece como si el artista no deseara desaprovechar la posibilidad que le ofrece la escultura de trabajar en relieve, explotando al máximo la tridimensionalidad de la escultura. Así, pues, parece que ya no cabe ninguna duda acerca de que en Cataluña existieron tanto las espadas de pomo discoidal plano como de pomo esférico. De este modo, las espadas extraídas de la miniatura o la pintura podrían presentar indistintamente el pomo plano o esférico.

Los sellos constituyen también una fuente muy reveladora en este sentido, pues en ellos se puede apreciar un intenso sombreado en el pomo, que, con toda probabilidad, alude a un carácter esférico del mismo ${ }^{37}$. Muy interesantes también son las espadas que aparecen en algunas monedas del condado de Ampurias, que, según Botet y Sisó,

cf. J. Ainaud de Lasarte, Pintures del segle XIII al carrer de Montcada de Barcelona (discurso leído en la Real Academia de Buenas Letras), Barcelona, Ariel, 1969.

36 Igualmente se puede observar la esfericidad del pomo en diversos capiteles de los claustros de las catedrales de Lérida y Tarragona. También en un capitel del castillo de Perelada y en la Urna de San Cándido (s. XIII).

37 Cf. F. Sagarra, op. cit., desde 1200 a 1311: tomo I, núms. 14, 20, 33, 49; tomo II, núms. 251, 2545, 2541, 2128, 1860, 1859, 1841, 2547, 252, 2283, 266. 


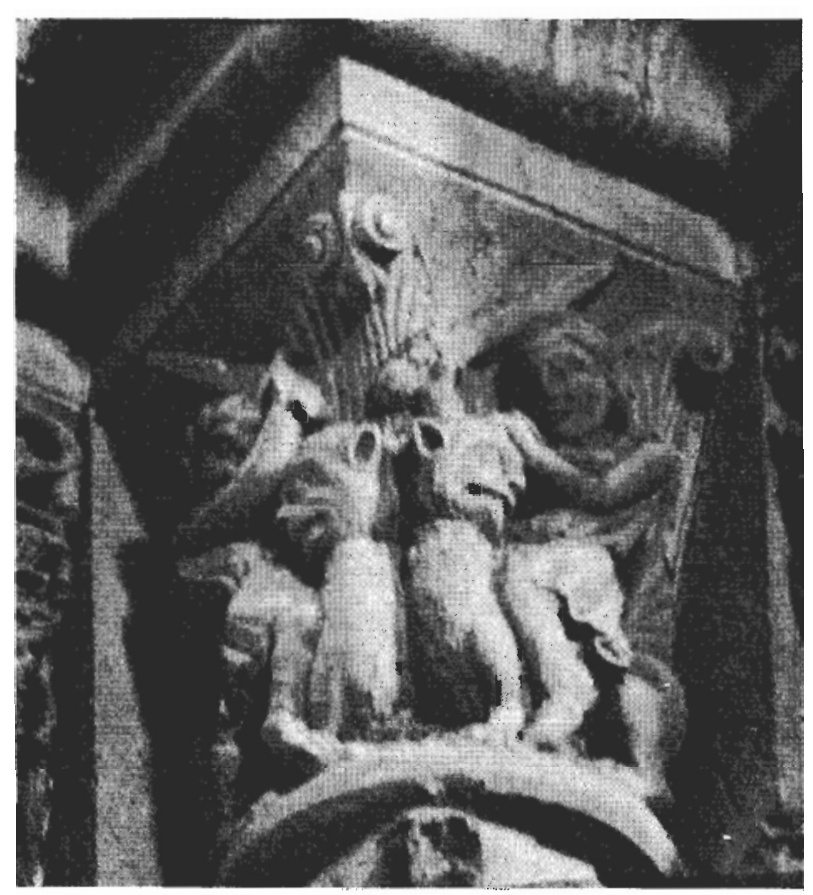

Foto VII.-Capiteles de la caledral de Lérida, s. xiII, capitel central: dos espadas tipo II
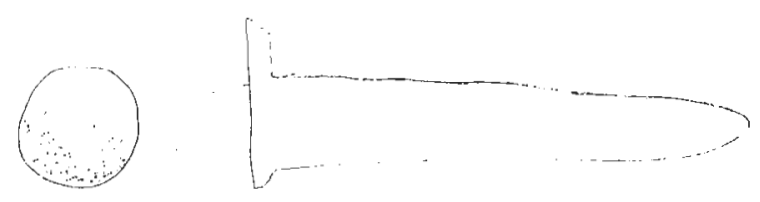

Tipo 1I, pomo esférico

pertenecen a finales del siglo xil y principios del siglo xIII. Estas podrían incluirse dentro del tipo II, aun cuando, en algunas ocasiones, no sea posible distinguir con precisión la forma del pomo ${ }^{38}$.

38 Cf. J. Botet y Sisó, Les monedes catalanes (3 vols.), Barcelona, 1908, números $115,116,117$. 


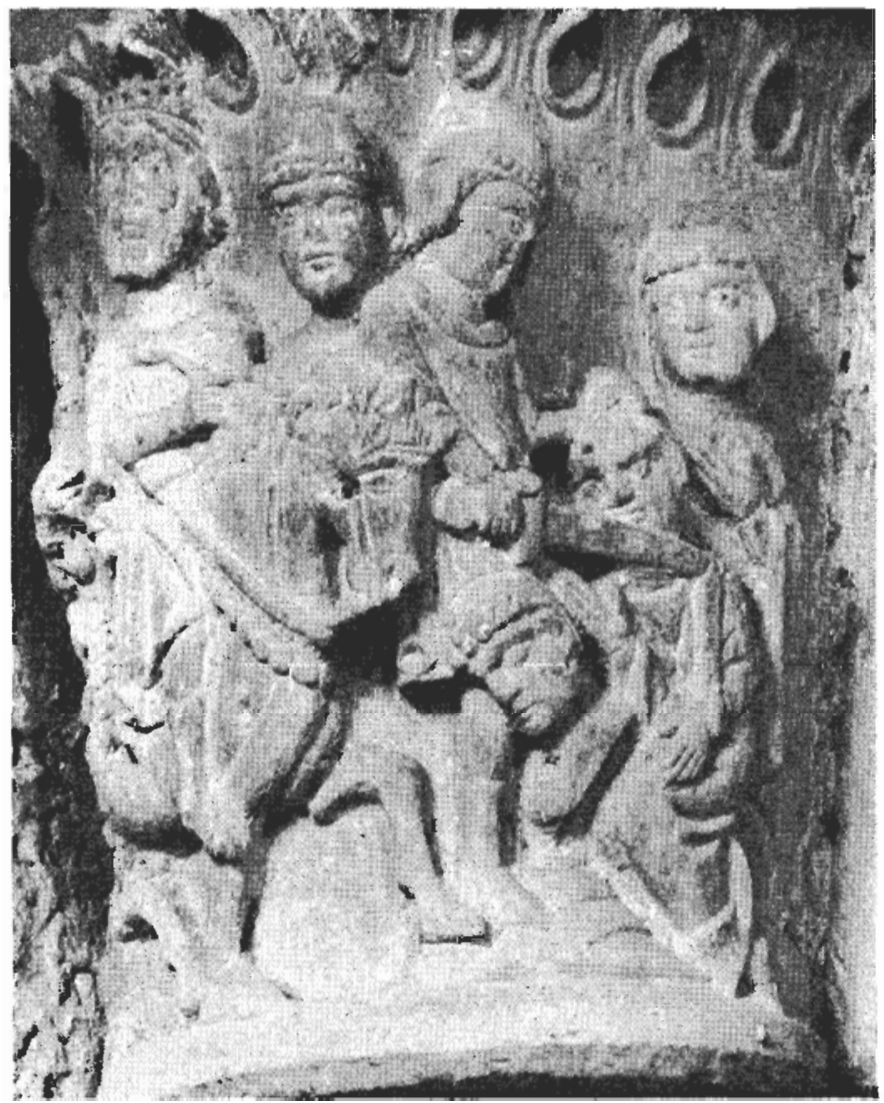

Foto VIII.-Capitel de la caledral vieja de Lérida (interior), s. XIII. Espada tipo II, pomo discoidal plano

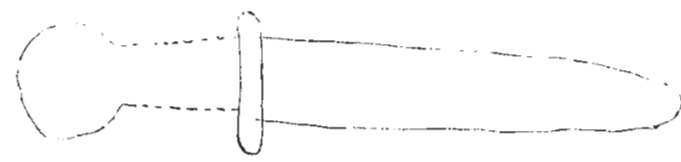


Las espadas tipo II son frecuentes en los museos de Europa. En especial, son muy abundantes las espadas de pomo discoidal plano. La Armería Estruch cuenta con un magnífico ejemplar del tipo II con pomo plano ${ }^{39}$. Del mismo tipo es una espada fechada por $H$. Seitz entre 1100 y 1200 de la colección Marcello Terenzi en Roma ${ }^{40}$. Ada Bruhn recoge varias piezas del Museo Nacional de Copenhague, así como del Kunstgewerbes de Düsseldorf. Todas ellas presentan un pomo discoidal plano y sus fechas oscilan entre 1150 y $1200^{41}$. Digna de mención es también la espada con la inscripción SESBENEDICTUS, hallada en Fornham y que E. Oakeshott fecha en el $1171^{42}$.

El tipo II aparece también en las fuentes iconográficas europeas, en especial en manuscritos y pintura mural de los siglos XII y XIII. Destaca el manuscrito de Heidelberg ( Pal. germ. 112, folio 5), en donde aparece Rolando llevando la «espada de la justicia» junto al sabio Olivier. Al igual que en el capitel de la catedral de Lérida, anteriormente citado, Rolando utiliza una espada tipo II ${ }^{43}$. En la basílica de Prüfening (cerca de Regensburg), en el pilar nordeste de la cruzada del transepto (segunda mitad del siglo xIII), aparece un San Pedro en el trono con dos espadas en alto del tipo II. En realidad, este tipo resulta muy extendido en toda la iconografía europea de la época, tanto en la alemana como en la francesa o italiana ${ }^{44}$.

A lo largo de este análisis se ha puesto de relieve la complejidad formal y cronológica del tipo II. En realidad, dicha complejidad reside principalmente en la disyunción establecida desde un principio: «pomo discoidal plano» o «esférico». De otro lado, resulta perplejizante el hecho de que carezcamos de ejemplos arqueológicos reales de espadas

39 Cf. García Llansó, op. cit., pág. 32.

40 Cf. H. SeITZ, op. cit., pág. 145.

41 Cf. A. BRUHN, Middelalderens, cit., tomo II, Pl. X (a-e).

42 Cf. E. OAKeshotT, op. cit., lám. 6.

43 Véase también en la Heidelbcrg Univcrsitätsbibliothek, Pal. germ. folio $11 \mathrm{v}^{n}$. «la toma legendaria de Córdoba por Rolando y Olivier», y del mismo Pal. germ., folio 19.

44 Presentan espadas de este tipo: la iglesia parroquial de Sankt Cyriacus en Berghausen en Sauerland: norte del ábside, la escena del sacrificio de Isaac (hacia 1200); en la Nikolauskirche, la escena de Adán y Eva, expulsados del paraíso (finales del s. XII); la iglesia de Santi Giovanni e Paolo en Espoleto, en la escena de la degollación de Santo Tomás Becket y en el martirio de los Santos Juan y Pablo (principios del s. xIII); la catedral de Aquileia (cripta), la escena de la degollación de los Santos Hermágoras y Fortunato (principios del s. XIII); Berzé-la Ville, en el ábside, la capilla de los monjes, escena de Saint Blaise en la prisión y martirio del Santo; Saint-Jacques-des Guérets, en el muro sur en la escena del martirio de San Juan ante Herodes (1200); Ebreuil-sur Allier, detalle de San Pancracio, tribuna oeste (fin del s. XII, principios del xiII). 
de pomo esférico. No hemos podido ofrecer aquí ningún ejemplo de este grupo. Pero Ada Bruhn expresa de forma muy clara: «It is not common but it does occur in some excavated finds in Denmark and in the West European region, especially England. Pictorially it appears several times in the Maciejowsky bible and in the Maness manuscript. Its period was apparently the 12 th and 13 th centuries» ${ }^{45}$. A esta afirmación agregaríamos tan sólo que en Cataluña también apareció en el siglo XIII, pues la escultura en que aparecen dichas espadas data de esta época. Los ejemplos existentes de sellos aportan fechas precisas desde el 1200 hasta el 1311. En realidad, no creemos que las espadas representadas en las Biblias o en el manuscrito de Tortosa presentaran pomos esféricos. Según nuestro modo de ver, el pomo esférico es más una evolución que una variante del pomo discoidal plano. De esta forma, lo congruente sería pensar que la iconografía de los siglos XI y XII representa pomos discoidales planos, mientras que en la del siglo XIII aparecerán indistintamente ambas formas, tal y como ha demostrado la escultura. De este modo, el período cronológico establecido para el tipo II abarcaría desde la segunda mitad del siglo XI hasta el primer cuarto del siglo xIV, perdurando la forma primitiva del pomo discoidal plano junto con la evolucionada de pomo esférico.

Tipo IIIa: Pomo CON ORNAMENTACión CONCÉNTRICA, ARRIAZ RECTO Scbeibenknauf mit konzentrischer Verzierung

En un principio, el tipo III reunía todas aquellas espadas que aparecían en la representación con una ornamentación concéntrica, dentro del pomo discoidal y un arriaz recto. La interpretación de dicha ornamentación resultó difícil en el momento en que percibimos la existencia de espadas con pomo seccionado en ambas caras (wheel pommel). Dichas espadas sólo podían representarse introduciendo en el pomo un círculo concéntrico. La diferencia entre una espada con ornamentación concéntrica de una con el pomo seccionado es patente. Por ello, aun cuando resultara en extremo difícil distinguirlas en la representación decidimos escindir el tipo III en dos grupos: tipo IIIa y tipo IIIb. Para ello consideramos que aquellos pomos que ofrecían más de un círculo concéntrico en su interior eran pomos con ornamentación concéntrica, mientras que los que sólo presentaban un círculo ligeramente sombreado aludían al pomo esférico seccionado. Posiblemente, este principio clasificatorio no resulte muy riguroso ni esté excesivamente fundamentado.

45 Cf. A. BruHn, Middelalderens, cit., tomo I, pág. 188. 
Sin embargo, ha de tenerse presente que el trabajo con fuentes iconográficas es difícil, dado que, en ocasiones, no son muy explícitas. Pero el historiador, como cualquier otro investigador, debe habituarse a solventar las lagunas, ya sea por escasez documental, ya por parquedad en su expresividad.

A pesar de todo, este principio clasificatorio no parece ser gratuito, pues los tipos IIIa y IIIb se adaptan perfectamente a la realidad.

El tipo IIIa se caracteriza por presentar varios círculos concéntricos en el interior del pomo, realizados, con frecuencia, a modo de incisión, y un arriaz recto (Fig. 3). Hemos de hacer notar que ese tipo no aparece dentro de las tipologías de E. Oakeshott o Ada Bruhn. Corresponde a los tipos 15 y 16 de H. Seitz, aunque tampoco con exactitud. Los tipos

Frg. 3.-Tipo IIIa

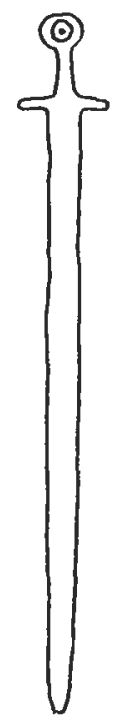

15 y 16 presentan un arriaz más complejo y, al mismo tiempo, su cronología es posterior a la nuestra $(1375-1474)^{46}$. Los ejemplos de espadas de pomos con ornamentación concéntrica que H. Seitz aporta se distinguirán netamente de nuestro tipo IIIa, siendo este último mucho menos complejo formalmente. El tipo IIIa se concibe como

46 Término de H. SeITz, op. cit.: konzentrischer Verzierung, Abd. 17; véase asimismo pág. 133, Abd. 75 (15-16). 
una variante evolutiva del tipo II. Deriva indudablemente del pomo discoidal plano, pues no se diferencia de éste más que en la ornamentación añadida al pomo. Se trata de un tipo que, debido a sus características formales, se adapta mejor a la miniatura o a la pintura que a la escultura o al sello. Para representar el tipo IIIa se necesita una gran escrupulosidad y un gusto por el detallismo por parte del artista. En la Biblia del Museo de Vich, tomo I, folio 36, aparece como ilustración al folio un extraño animal antropomórfico sosteniendo una interesante espada. El pomo está rodeado de tres círculos y se alternan tonos oscuros y claros. El arriaz es recto y en su interior se ha trazado un dibujo que podría referirse a los clavos que algunos arriaces tenían en sus extremos (Foto IX). En la zona superior izquierda del Frontal de Chía se representó a un San Martín cortando la capa. La pintura perte-

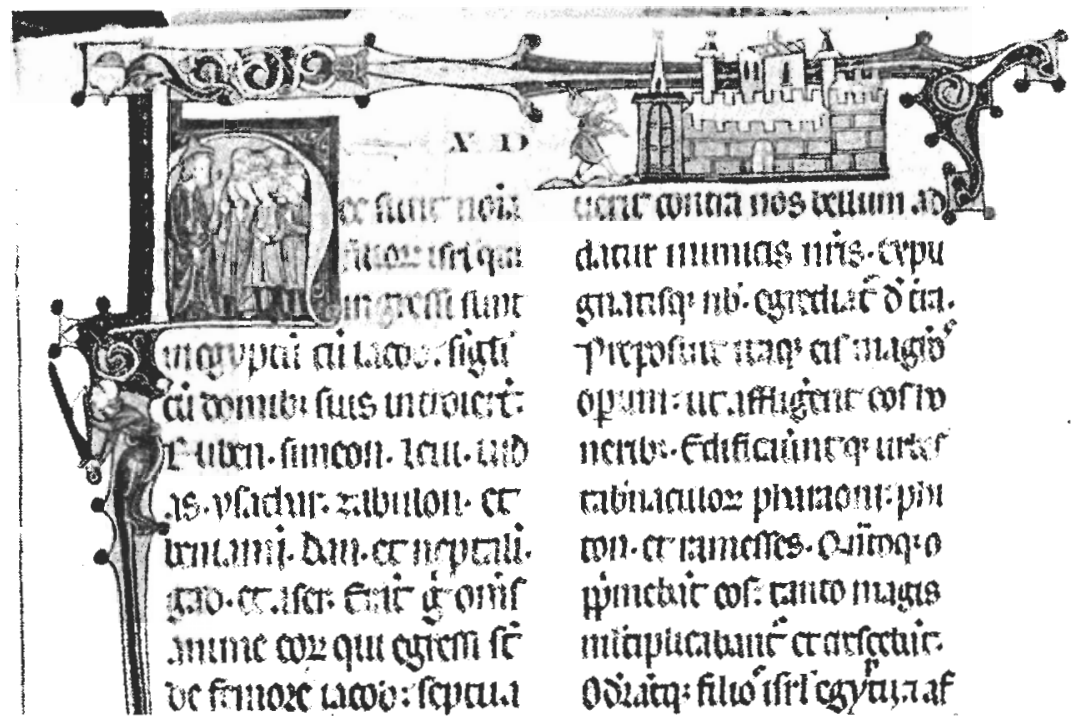

Foto IX.-Biblia del Museo de Vich, tomo I, folio 36, 1268, zona sup. izq.: Espada tipo IIIa

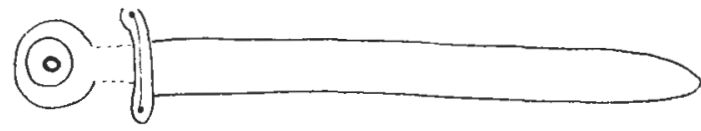




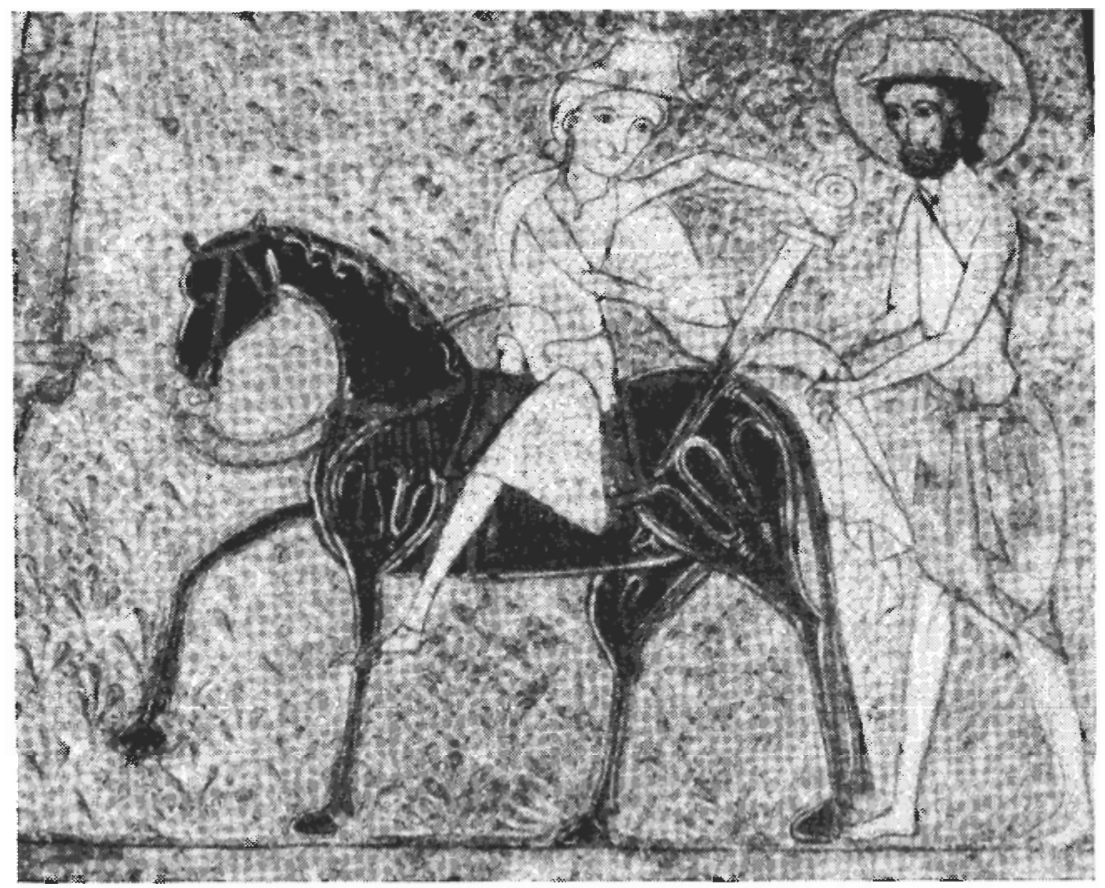

Foto X.-Frontal de Chía (Huesca), s. XiI-XiII: San Martín cortando la capa, M. A. C., sala 39. Espada tipo IIIa

nece a la primera mitad del siglo XIII y la espada utilizada por San Martín presenta varias incisiones en el interior del pomo (Foto X) ${ }^{47}$. Estos ejemplos resultan muy interesantes, pero debemos advertir que el tipo IIIa no habría sido introducido en este estudio si no fuera por la extraordinaria maestría y habilidad que demostró aquel magnífico escultor que realizara el relieve en la puerta de San Ivo de la Cateral de Barcelona hacia el año 1300. Denotando una gran calidad

47 Muy semejantes a éstas son las dos espadas que llevan dos caballeros en la pintura sobre tabla dedicada a San Pedro, de Bobí (s. XiII). 
artística esculpió una espada cuyo pomo está recorrido por varios círculos concéntricos (Foto XI). La espada de San Ivo constituye la representante genuina del tipo IIIa, puesto que la observación directa de esta espada excluye todo tipo de dudas acerca de lo que es un «pomo discoidal con ornamentación concéntrica». De otro lado, no nos ha sido posible aportar ejemplos de espadas reales de este tipo, pues las que cita $H$. Seitz responden a fechas posteriores. Sin embargo, es obvio que

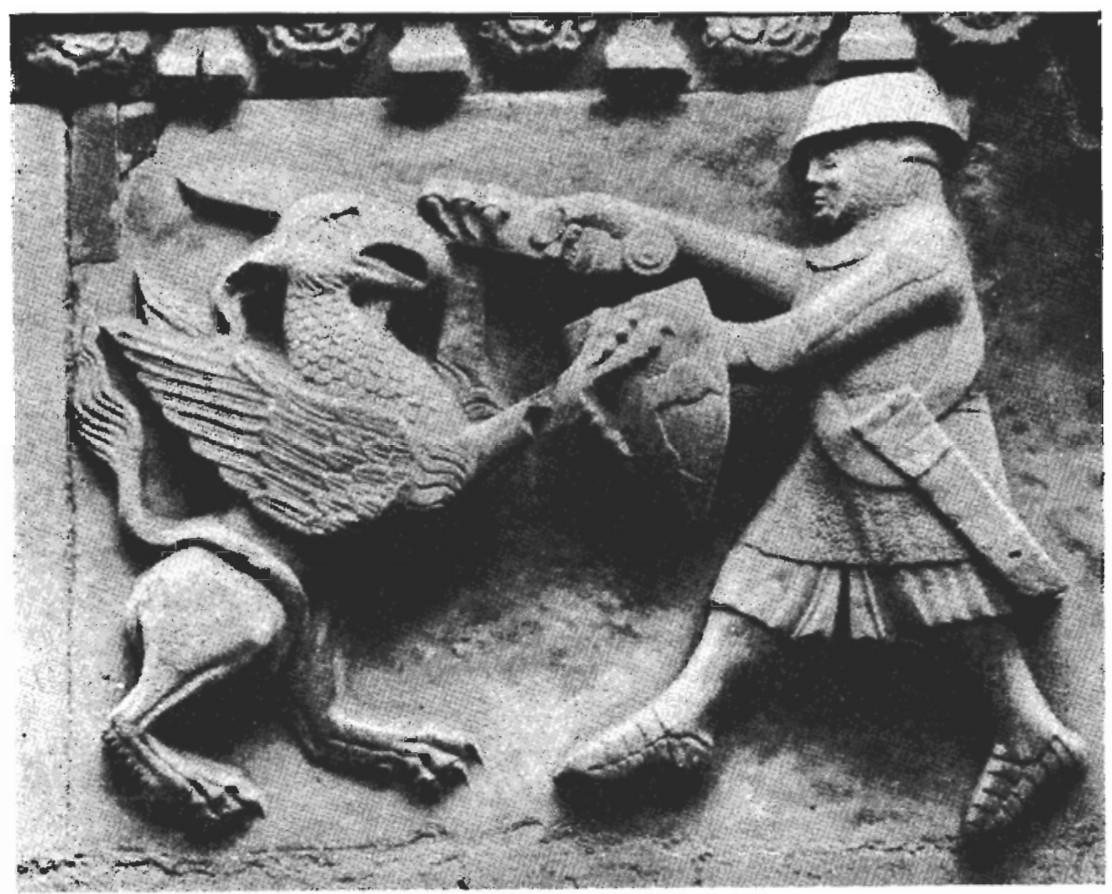

Foro XI.-Detalle de la Puerta de San Ivo, catedral de Barcelona, s. XiII

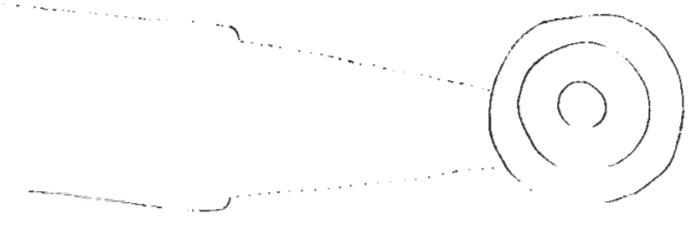


la espada de pomo con ornamentación concéntrica existió en Cataluña, al menos en el siglo XIII, dado que no resulta posible concebir que un artista como el de la puerta de San Ivo representara con toda fidelidad el armamento defensivo del caballero - ausberg con el capmall, el capell de ferro, los refuetzos de los brazos y las calzas de hierro ${ }^{48}$ - y, al mismo tiempo, inventara una forma de espada inexistente en la realidad. El maestro que ejecutara la puerta de San Ivo representó, sin ningún género de dudas, el armamento que vio; un tipo de espada utilizada por los caballeros catalanes de hacia 1300 .

Tipo IIIb: Pomo esférico Seccionado por ambas caras, ARRIAZ RECTO

Wheel-pommel and straight quillon

El tipo IIIb se concibe como una evolución del tipo II de pomo esférico. La única diferencia consiste en que el pomo esférico aparece aquí seccionado por ambas caras (Fig. 4). Nuestro tipo IIIb se adapta

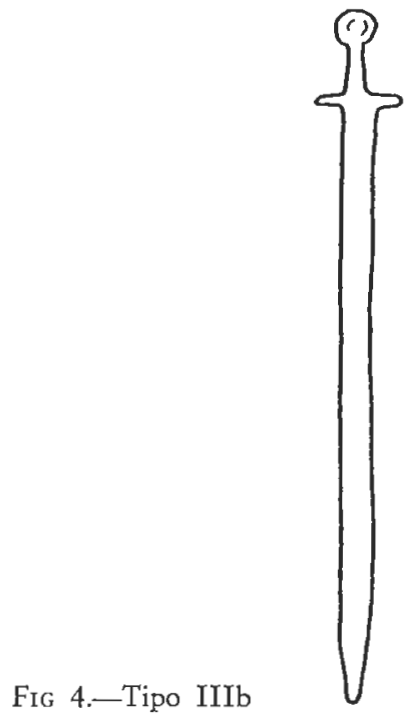

48 M. DE Riquer, L'arnès, cit., estudia con detalle el armamento defensivo del caballero de San Ivo, citado varias veces, pág. 27 hasta 48. 
al tipo XII de E. Oakeshott ${ }^{49}$ y al grupo IIIc de Ada Bruhn. Son usuales en este tipo las inscripciones de IN NOMINI DOMINI y GICELIN ME FECIT ${ }^{50}$. Los especialistas consideran que este tipo aparece a mediados o finales del siglo XII hasta principios o mediados del siglo XIV ${ }^{51}$. Una excelente espada aparece representada en un salte-

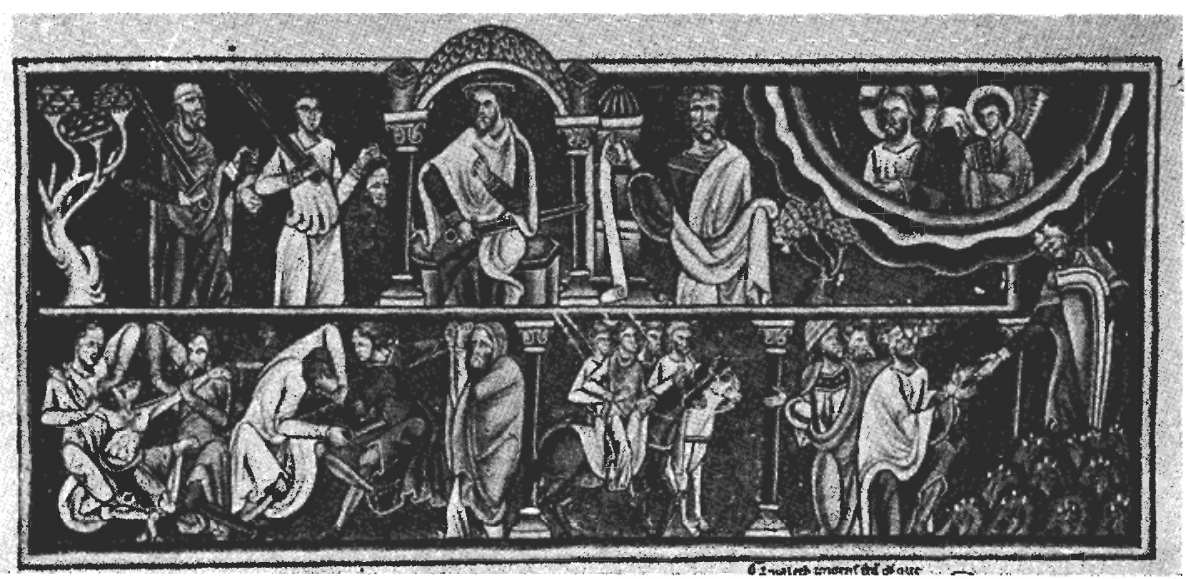

Foto XII.-Salterio catalán, París, Bibl. Nac., fol. 92 anverso, s. XII, zona superior izquierda: Espada tipo IIIb

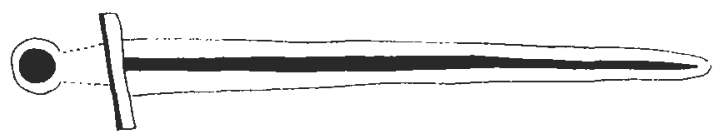

rio catalán conservado en la Biblioteca Nacional de París (fol. 92 anverso) (siglo XIII). El perfecto sombreado circular en el interior del pomo se refiere al carácter seccionado del pomo. La hoja ha sido trazada con gran cuidado, remarcando con decisión la canaladura central (Foto XII). Existen varios ejemplos de este tipo IIIb en distintas ilus

49 Cf. E. OAKeshott, op. cil., pág. 206.

50 Cf. A. Brunn, Middelalderens, cit., págs. 188, 189.

51 Según A. Brunn, op. cit., tomo I, se extiende desde 1150 hasta 1350 , página 189. E. OAKESHOTT, op. cit., opina que la cronología se extiende desde el 1180 hasta 1320 , pág. 206.

40 
traciones de la Biblia de Vich ${ }^{52}$. Todas estas espadas corresponden a la segunda mitad del siglo XIII. Un período similar (1258-1272) nos lo concede un sello de Ramón, vizconde de Cardona: la espada que alza el vizconde corresponde también al tipo IIIb $^{53}$. Y en una moneda de los condes de Ampurias, fechada por J. Botet y Sisó a finales del siglo XIII, se representó una espada que ofrece también las características de este tipo ${ }^{54}$.

Numerosas piezas arqueológicas responden al tipo IIIb. Uno de los mejores ejemplares se encuentra en el convento de Las Huelgas (Burgos). Se trata de la espada de la tumba de Fernando de la Cerda, fechada en $1270^{55}$. El Museo Nacional de Copenhague, el de Oslo, Basilea y la misma Wallace Collection poseen varias espadas con el pomo esférico seccionado y el arriaz recto. Ada Bruhn las sitúa cronológicamente entre el 1200 y el $1320^{56}$. Si bien el tipo IIIb no es muy común en la iconografía, tanto europea como catalana, parece ser que éste es un tipo corriente dentro del estilo de espada románica. Según la iconografía utilizada por nosotros, esta espada no aparece en Cataluña antes del 1268, siendo utilizada en la segunda mitad del siglo xiII.

\section{Tipo IVa: Pomo discoidal plano o esférico, arriaz arqueado}

Flat disc-pommel or spherical pommel and curved quillon

Si bien en el tipo III se impuso una división basada en la distinta forma del pomo, el tipo IV se escindirá en dos grupos debido al arriaz. No nos ha parecido oportuno tratar indistintamente el arriaz arqueado

52 Véase la espada que aparece en la ornamentación de la letra inicial del folio 386 v $^{0}$ del tomo III de la Biblia de Vich. En el folio 5 de la Biblia de Ripoll aparece en la zona inferior un ángel con una espada. El pomo presenta en el centro un pequeño punto. No creo que dicha marca deba entenderse como una alusión al pomo seccionado; en primer lugar, porque esta representación no resulta similar a las ya analizadas y, en segundo lugar, porque si el tipo IIIb es una evolución, como todo parece indicar, del tipo II, es incongruente que a finales del siglo XI aparezcan ya espadas con pomo esférico seccionado. Parece ser que este tipo de pomo con el punto en el centro estaba inspirado en formas de origen oriental. De todas formas, el hecho de que no vuelva a aparecer en ninguna de las fuentes por nosotros estudiadas podría indicar que no constituyó un tipo muy usual.

53 Cf. F. Sagarra, op. cit., t. II, n. 2068.

54 Cf. Botet y Sisó, op. cit., n. 120 . Cf. también J. E. Cirlot, la espada en la moneda, cit., pág. 20.

55 C. E. ÓAKESHOT'T, op. cit., lám. 9 (c).

56 Cf. A. BRuHN, Middelalderens, cit., t. II, Pl. XII-XVI. 
(curved quillon) y el arriaz en forma de gancho (booked quillon), por lo que ambos arriaces conformarán dos variantes. Al mismo tiempo, la diferencia no nos ha parecido lo suficientemente importante como para separarlos en tipos distintos.

El tipo IVa vuelve a plantear el mismo problema del tipo II. Los pomos aparecen representados en pintura y miniatura generalmente en forma plana y no resulta posible distinguir si se trata de un pomo esférico o discoidal plano. Sin embargo, el tipo IVa se fundamenta en la forma específica del arriaz. El arriaz arqueado transforma en su estilo y aspecto a la espada de tipos anteriores. A nuestro modo de ver, arriaz recto y arriaz arqueado no deben incluirse dentro de un mismo

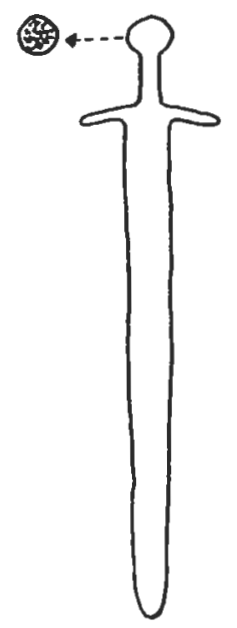

FIG. 5.- Tipo IVa

tipo, sino que, por el contrario, deben distinguirse con toda claridad. El arqueamiento del arriaz varía considerablemente de una espada a otra. A veces resulta más pronunciado y otras poco sobresale de la anchura de la hoja. De cualquier forma, en la época tratada por nosotros el arriaz no se arquea muy acusadamente hacia abajo. Dicha forma corresponderá mejor a las espadas de los siglos xIV y xV (Fig. 5). Nuestro tipo IVa corresponde al grupo IIIb de Ada Bruhn, que según su propia autora resulta muy poco común. Notemos que Ada Bruhn no introduce en su grupo IIIb la posibilidad de pomo esférico, refiriéndose tan sólo al «disc-pommel, curved quillon» ${ }^{57}$. El tipo IV no

57 Ibídem, t. I, pág. 188. 


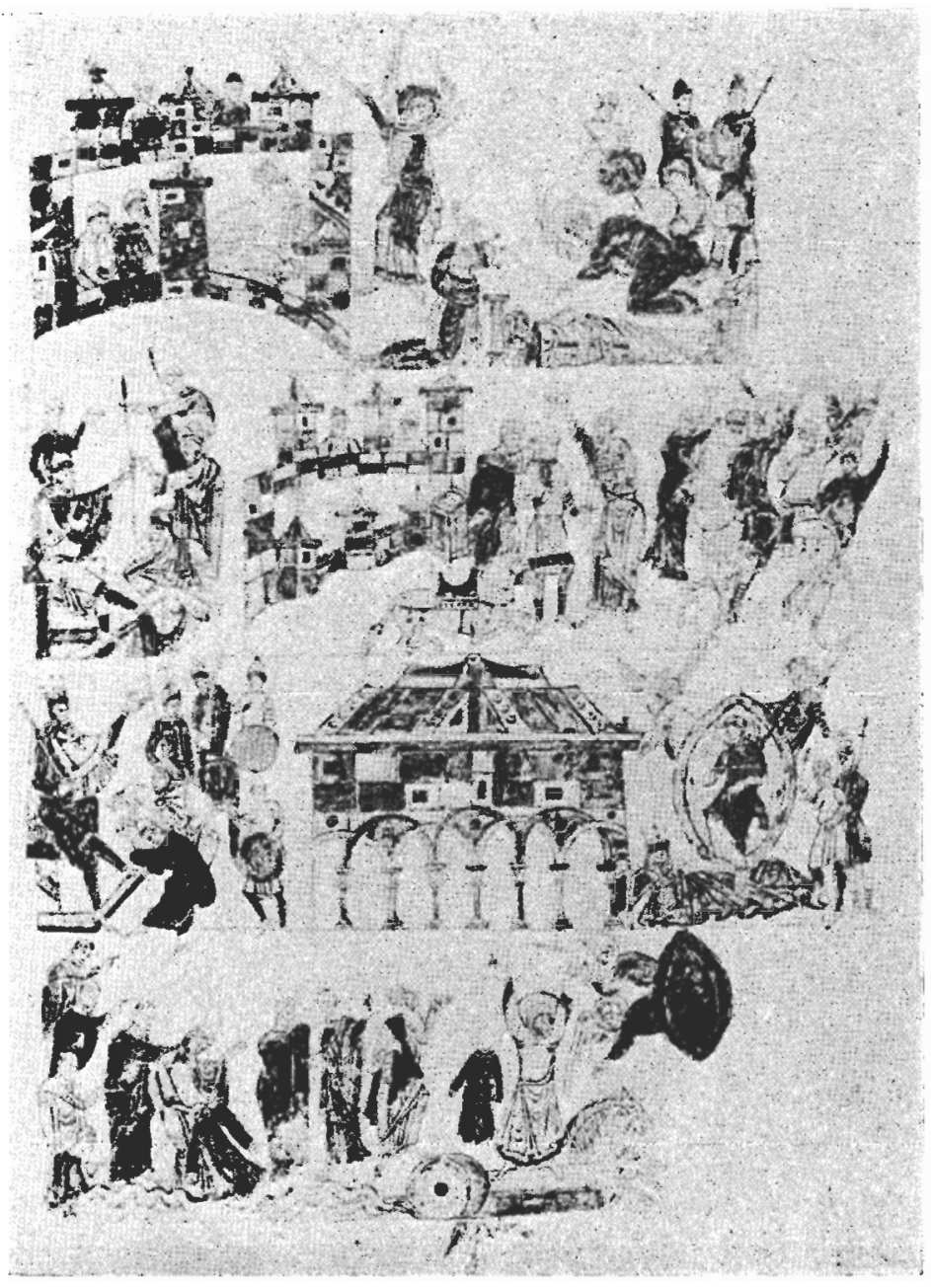

Foro XIII.--Biblia de Ripoll, f. 95. Zona central izquierda: Espada tipo IVa

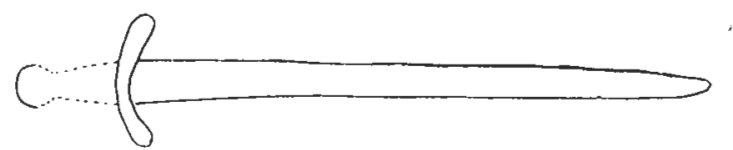


se adecúa ni a la tipología de E. Oakeshott ni a la de H. Seitz, pues ninguno de los dos autores considera el arriaz como elemento diferenciador.

Podría considerarse que el arriaz arqueado procede de una evolución formal del arriaz recto de época vikinga. Parece ser que el arriaz arqueado aparece por vez primera en el siglo xI. En el folio 95 de la Biblia de Ripoll, en la zona inferior izquierda, aparece un guerrero sosteniendo una espada con un arriaz claramente arqueado (Foto XIII). Parece ser que el arriaz arqueado conforma un tipo de espada que aparecerá ya en la segunda mitad del siglo XI. Una extraordinaria miniatura del Liber Feudorum Ceritaniae nos muestra una escena de enfeudamiento. El caballero que ofrece sus manos al señor lleva una espada envainada que cuelga del cinto. El arriaz aparece arqueado y el pomo se encuentra ligeramente sombreado por su parte inferior (Foto XIV). Podría tratarse de un pomo esférico, aunque resulta difícil apreciarlo con exactitud. La existencia de espadas tipo IVa de pomo esférico la constató el maestro de Bohí. En la pintura mural de San

Foro XIV. - Tiber Fctudorum Ceritaniae, A. C. A., Cancillería
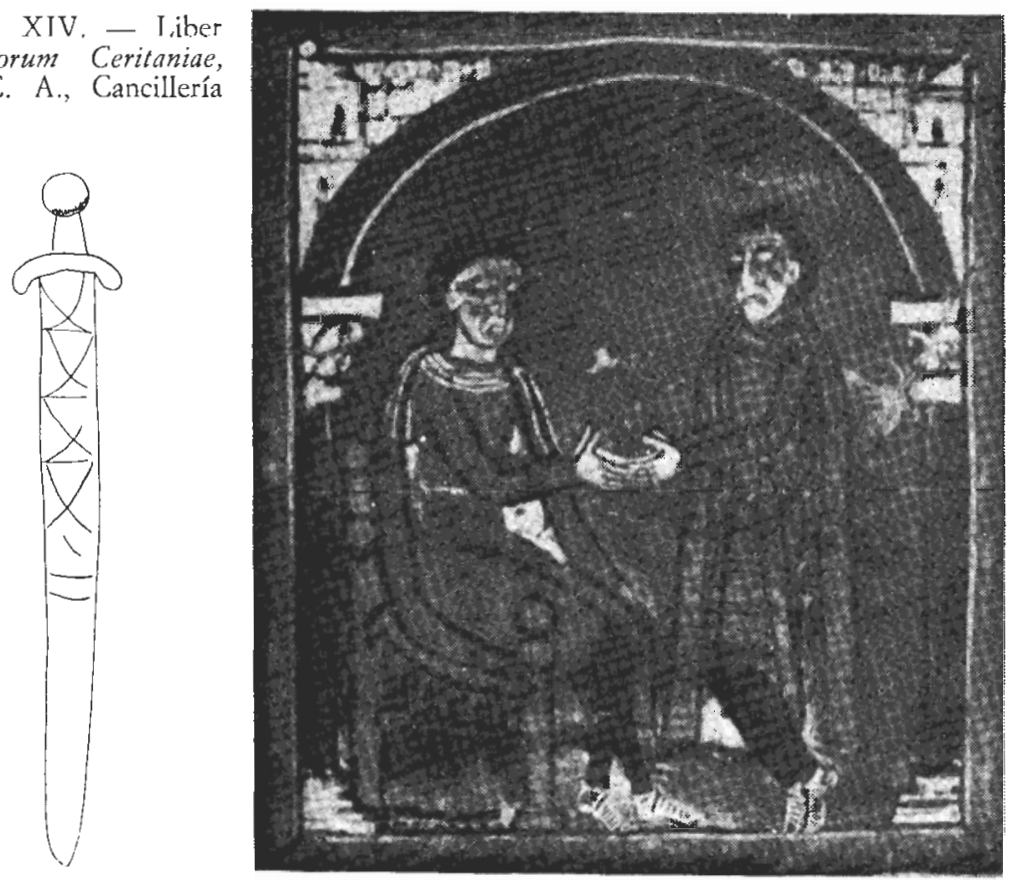


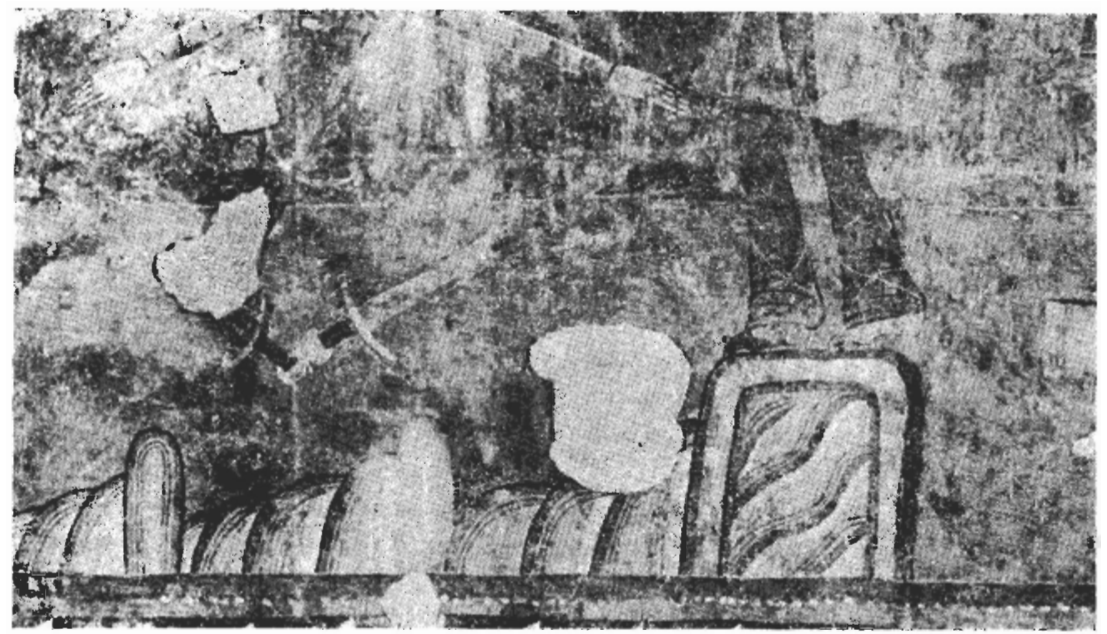

Fото XV.-Decoración mural de San Juan de Bobi (s. XiI), M. A. C., sala 4, zona inferior izquierda: tres espadas tipo IVa

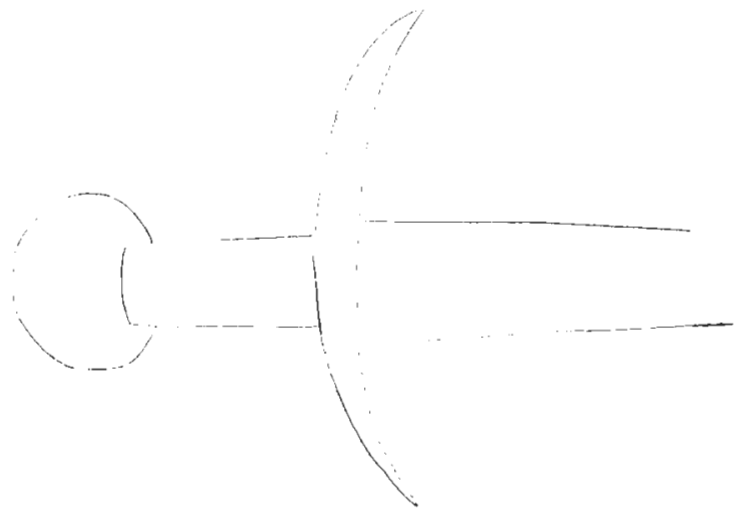

Juan de Bobi (zona central inferior) destacan tres espadas realizadas con una fidelidad extraordinaria. Las tres presentan el arriaz arqueado y en dos de ellas se puede apreciar sin dificultad el carácter esférico del pomo (Foto XV). La decoración mural de San Juan de Bohí ha sido fechada por los especialistas en la primera mitad del siglo XI o 
en el siglo XII ${ }^{58}$. Sin embargo, estas espadas deben fecharse, por su tipología, entre el 1200 y 1300 . La extraña posición que asumen estas tres espadas dentro del conjunto pictórico podría deberse a una posible superposición posterior cronológicamente al resto de la pintura. De cualquier forma, no es posible concebir que estas espadas correspondan al siglo XII, no sólo ya por la esfericidad indudable del pomo, sino porque en conjunto se trata de un tipo evolucionado que no corresponde al usual del siglo xII.

Los frescos que decoraron el castillo catalán ofrecen numerosas representaciones de este tipo de espadas. La escena de la lucha del caballero contra el monstruo (pared 3, zona izquierda) presenta una espada tipo IVa. Y en otra escena (pared 1, zona izquierda) se observan dos espadas de las que sólo se puede apreciar la hoja y el arriaz arqueado. El resto de la empuñadura queda oculto en la representación (Foto XVI). En estos casos nos hemos permitido reconstruir la empuñadura siguiendo las formas de anteriores ejemplos. En los siglos XII y xiII, el arriaz arqueado aparece acompañado de un pomo discoidal plano o esférico ${ }^{59}$.

A pesar de que en las fuentes iconográficas no escaseen ejemplos de espadas tipo IVa, hay que destacar que no se han encontrado demasiadas piezas arqueológicas correspondientes al tipo en cuestión. En la Armería Estruch existe una espada de finales del siglo xin que se adapta perfectamente al tipo IVa ${ }^{60}$. Quizá, la espada más conocida y más representativa de este tipo sea la que se encuentra en la Wallace Collection. Dicha espada presenta un pomo discoidal plano y el arriaz arqueado, con los extremos ligeramente redondeados. J. Mann la fecha en el siglo XIII, mientras que Ada Bruhn la sitúa entre 1175 y $1200{ }^{61}$.

Sin embargo, a pesar de que este tipo no encuentre abundantes ejemplos reales, es común en la iconografía tanto catalana como europea. En una miniatura del manuscrito Corpus Christi College 157, folios 382-383 de Oxford, fechado en el siglo xil, aparece un caballero con una espada tipo IVa. En una vidriera de Chartres, conservada en la catedral de Notre-Dame, de principios del siglo xIII, Rolando utiliza

${ }^{58}$ Cf. W. W. S. Cook, Pintura e imaginería románicas, «Ars Hispaniae», Madrid, 1950, págs, 31-32. Cf. O. Demus, M. Hirmer, La peinture murale romane, Paris, Flammarion, 1970, pág. 73.

59 Espada de arriaz arqueado y pomo plano o esférico aparece también en el Frontal de Bolvir, dedicado a Santa Cecilia (s. xrrr). Asimismo una de las monedas del condado de Ampurias del siglo xrrr ofrece una espada con un arriaz arqueado de forma muy acusada.

oo Cf. García Llansó, op. cit., pág. 32, n. ${ }^{\circ} 2$.

61 Cf. J. Mann, op cit., A 458 Sword, plate 105, y of. A. BruHn, Middelalderens, cit., t. II, Pl. XI. 


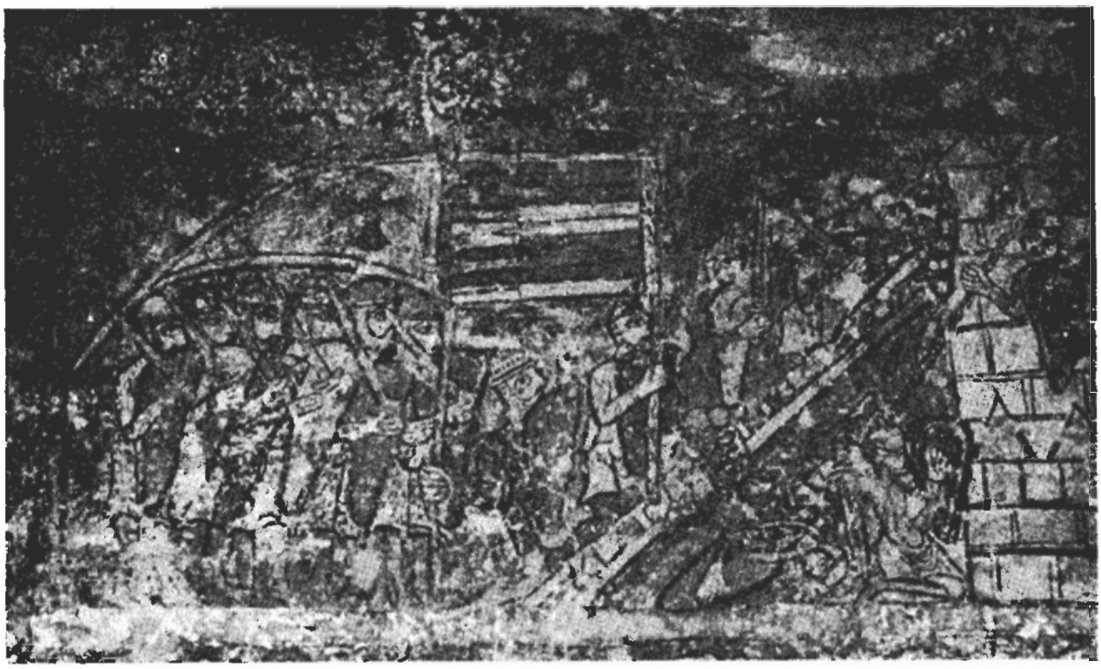

Fото XVI.-Castillo catalán, posiblemente de Urgellet, s. XırI, M. A. C., sala 27 , espadas tipo IVa

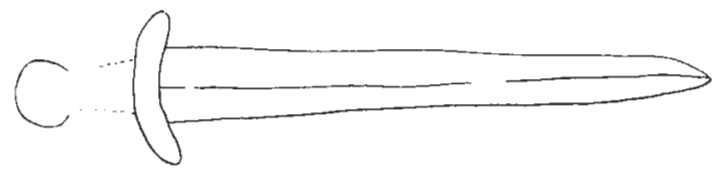

en el combate contra Ferragut una espada de arriaz arqueado y pomo discoidal. Asimismo las dos espadas representadas en el registro inferior de una miniatura del Codex Calixtinus, de Santiago de Compostela (folio 162). El fresco de la leyenda de San Alexis, en la iglesia de San Clemente, en Roma, fechado hacia 1100, muestra una espada de arriaz arqueado con un pomo posiblemente discoidal plano. El mismo tipo de espada aparece en la escena de la «masacre de los inocentes» en Brinay-sur-Cher, Saint Aignan (muro este del coro), de la segunda mitad del siglo xiI, o en la escena del «combate de los ángeles contra los demonios» en la iglesia de Saint-Savin-sur-Gartempe (Porche). Aun cuando es obvio que los ejemplos podrían multiplicarse, creemos que éstos ya resultan suficientes para demostrar que el tipo IVa se utilizó en Europa desde el año 1100 hasta finales del siglo xiıI, cronología que responde totalmente a la constatada por nosotros en la iconografía catalana. Destaquemos que la variante de pomo esférico es posterior y no aparecerá hasta el 1200 aproximadamente. 
TIPO IVb: POMO DISCOIDAL PLANO O ESFÉRICO, ARRIAZ EN FORMA DE GANCHO

Flat disc-or spherical pommel and booked quillon

Se trata de un tipo poco común, pero interesante. El elemento que lo caracteriza es precisamente la «forma de gancho» del arriaz (Fig. 6).

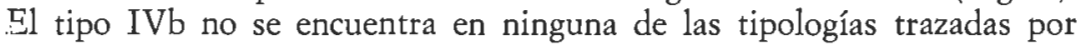
los especialistas. Ada Bruhn introduce el concepto de «hooked quillon», pero lo constata en piezas correspondientes a los siglos XIV y xv. El grupo IIId de Ada Bruhn no corresponde a nuestro tipo IVb, pues el primero presenta unas formas de pomo muy complejas, que difieren un tanto de las nuestras ${ }^{62}$. El interés del tipo IVb reside en que

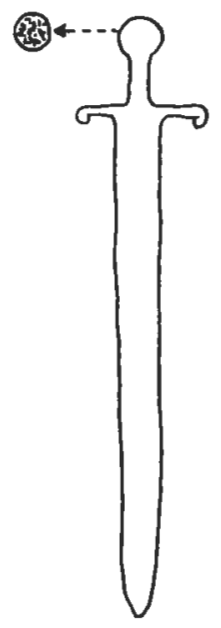

FIG. 6.-Tipo IVb

se trata de una variante evolutiva del tipo IVa. Al mismo tiempo, el tipo IVb generará, a su vez, tipos de espadas importantes en siglos posteriores. En realidad, el origen del grupo IIId de Ada Bruhn, tipo de la espada gótica, es un resultado de la evolución del tipo IVb. De cualquier forma, se imponía la clasificación de un tipo que, aunque no muy frecuentemente, aparece en la iconografía catalana.

Un capitel de la catedral vieja de Lérida nos ofrece un ejemplo de arriaz en forma de gancho. La espada presenta un pomo esférico

62 Cf. A. Bruhn, Middelalderens, cit., t. II, PI. XXIX. 
(Foto XVI1). Este tipo vuelve al aparecer en otros capiteles de la misma catedral. También en una escena del castillo catalán. La espada de esta pintura mural se distingue por su simplicidad formal, muy acusada. El arriaz es el único elemento que presenta en su morfología

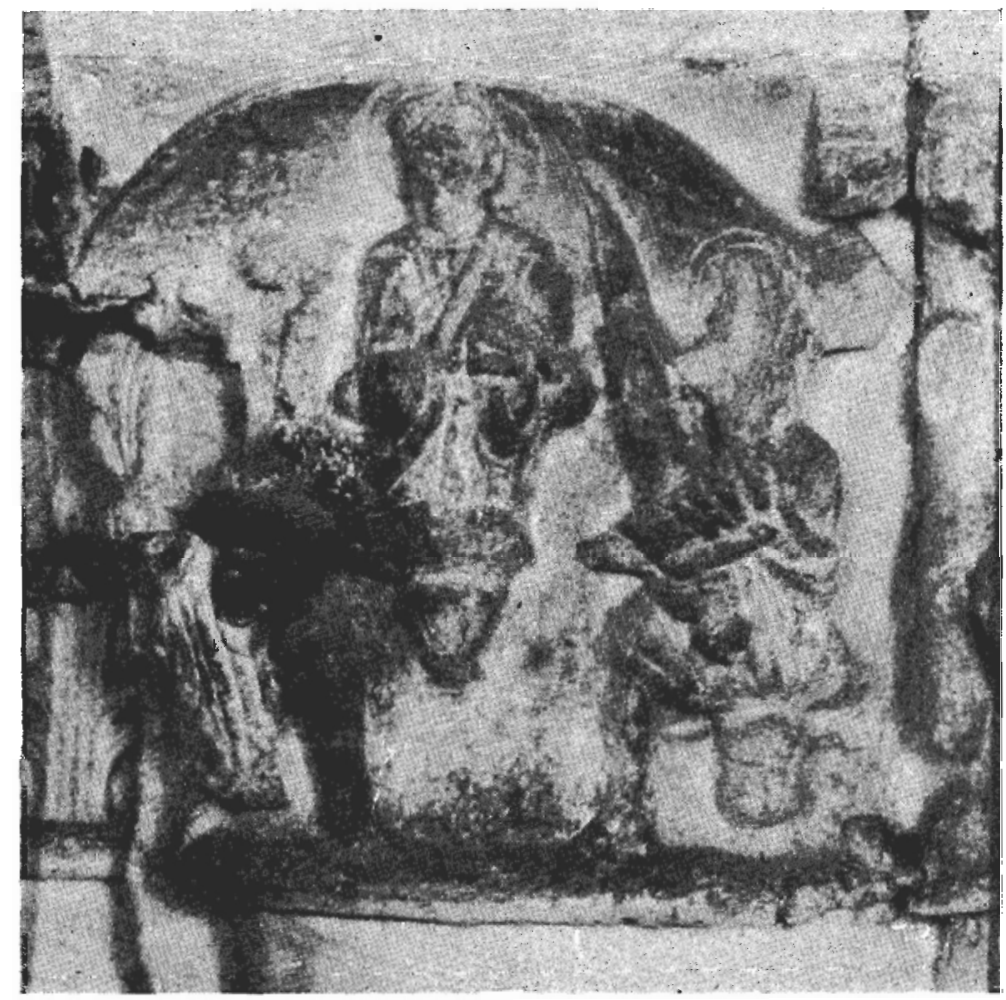

Fото XVII.-Capiteles de la catedral vieja de Lérida (interior), s. xIII. Capitel central: Espada tipo IVb

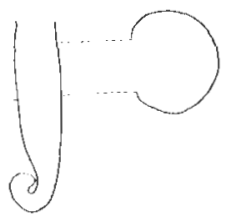


una ligera complicación: sus extremos caen perpendiculares al arriaz, hacia abajo.

Debemos advertir que no contamos con ningún ejemplo que corresponda a este tipo IVb. Las espadas con arriaz en forma de gancho que se conservan presentan una complejidad formal de todos los elementos. Ello obliga a incluirlas dentro de un claro estilo gótico. Sin embargo, la iconografía europea sí puede ofrecernos algún ejemplo similar a este tipo. En un mosaico de Vercelli (Museo Leone), que narra el Combat $d u$ foi et $d u$ fel, aparecen dos espadas con inscripciones y con el arriaz muy semejante al de la espada del castillo catalán. El mosaico está fechado en el año 1148. Muy semejante también a esta espada es la que empuña Rolando en la fachada de la iglesia de Notre-Dame-de-la-Règle, en Limoges (ahora en el Museo de Bellas Artes en Limoges).

A pesar de que parece que este tipo se conoció en Europa ya en el siglo XI, en la iconografía catalana aparece en el siglo XIII y no anteriormente. A mi modo de ver, el tipo IVb es una evolución del IVa, que, como ya vimos, aparecía en las Biblias de Roda y de Ripoll, utilizándose hasta finales del siglo XIII. Así, pues, en el siglo XIII coexistieron, como observamos en el caso anterior, ambas formas de arriaces: la primitiva y la evolucionada.

\section{TIPO V: POMO CON ORNAMENTACIÓN CONCÉNTRICA O ESFÉRICO SECCIONADO, ARRIAZ EN FORMA DE GANCHO}

\section{Wheel-pommel and booked quillon}

En el tipo V confluyen el tipo IIIa (ornamentación concéntrica) y el tipo IIIJ (pomo seccionado en ambas caras) en lo que se refiere a la tipología del pomo; el tipo IVb (arriaz en forma de gancho) en lo que respecta al arriaz (Fig. 7). Es éste un tipo de espada complejo y que trae consigo serias dificultades a la hora de su interpretación. Nuestro tipo $\mathrm{V}$ se adapta en cierta forma al grupo IIId de Ada Bruhn, aunque en dicho grupo no se incluyan los pomos de ornamentación concéntrica ${ }^{63}$. Corresponde al tipo XV de E. Oakeshott, tipo que, según su propio autor, aparece en la segunda mitad del siglo XIII ${ }^{64}$. Así, pues, se ha considerado que el punto de partida para este tipo debe situarse en la segunda mitad

63 Ibídem, t. I, pág. 191.

64 Cf. E. OAKESHOTT, op. cit, pág. 307. 
del siglo xIII, viviendo un pleno desarrollo en los siglos xIV y $\mathrm{xV}$, época en que al pomo se le añade el botón que transformará la morfología de la espada ${ }^{65}$. La complejidad formal de este tipo hace pensar en una fecha de aparición tardía. Sin embargo, en la pintura de San Martín Sescorts, fechada por los especialistas en el primer cuarto del siglo XII, aparece una espada con un círculo concéntrico en el

FIG. 7.-Tipo V

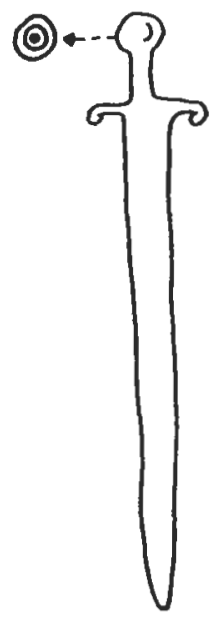

interior del pomo, que alude de modo inequívoco al pomo seccionado; el arriaz tiene sus extremos en forma de gancho (Foto XVIII) ${ }^{66}$. Según la propia congruencia de nuestra tipología, esta espada correspondería al siglo XIII, y la pintura de San Martín Sescorts podría ser en realidad posterior a la fecha adjudicada por los especialistas del arte. Pero también podría suceder que este tipo $\mathrm{V}$ no resultara de una evolución estilística de los tipos anteriores, sino que hubiera surgido de una influencia exógena, posiblemente oriental. De cualquier forma, los demás ejemplos de iconografía catalana que poseemos de este tipo pertenecen ya al siglo XIII. Una espada tipo $\mathrm{V}$ aparece en una ilustración de la Biblia de Vich, fechada en 1268. Una muy similar

65 Cf. A. BruHn, Middelaldernes, cit., t. II, P. XXVII.

66 En una ilustración de la Biblia de Roda aparece una espada, en cuyo pomo se ha dibujado en su interior un punto y cuyo arriaz se arquea de modo que sus extremos adoptan la forma de gancho. Se trata de una espada difícil de tipologizar, pues no corresponde de forma exacta al tipo $\mathrm{V}$. 


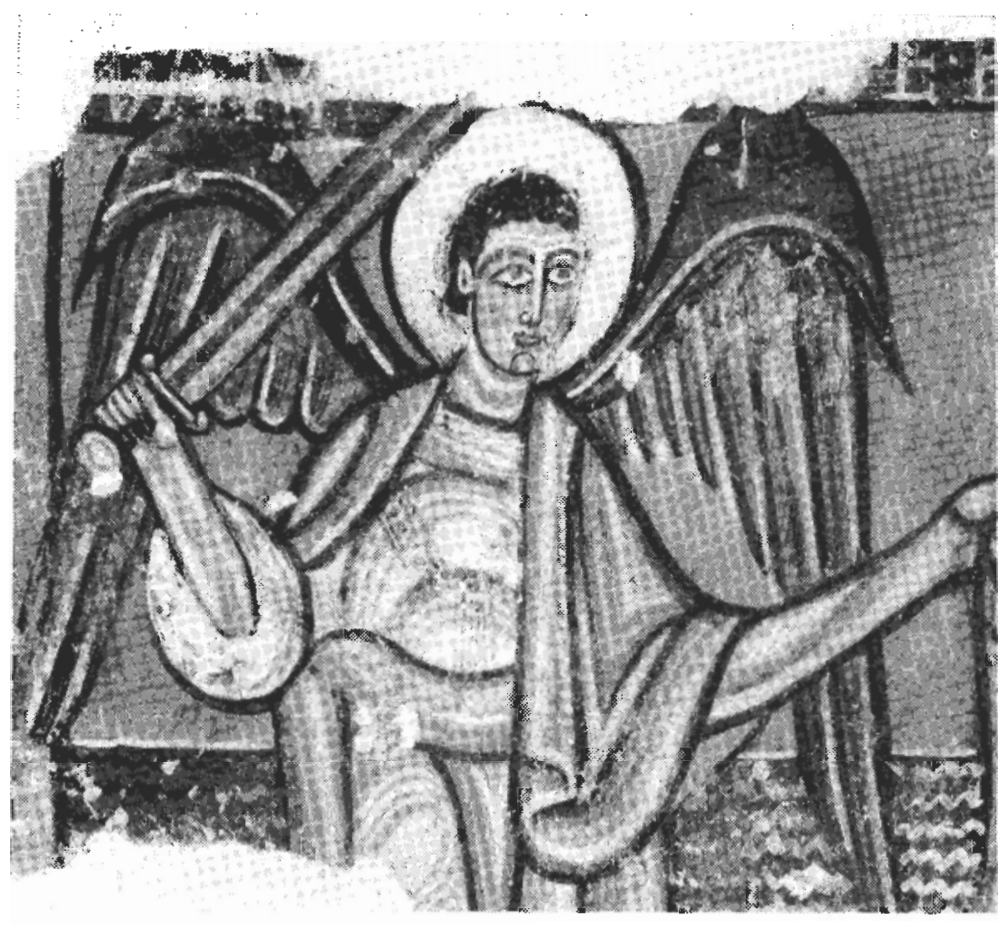

Foro XVIII.-Detalle de la pintura de San Martín Sescorts, Museo de Vich

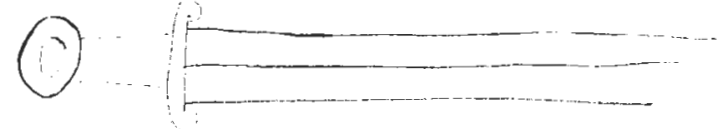

a la anterior aparece en el folio 92 de un salterio catalán de la Biblioteca Nacional de París ${ }^{67}$.

Como ya se ha advertido, los especialistas constatan este tipo V en espadas de fechas posteriores. Sin embargo, la Wallace Collection posee una espada con pomo seccionado por ambas caras y arriaz ar-

67 Asimismo la espada que el caballero sostiene en alto en la Viga transversal de Cardet (s. xiII) y la espada del frontal de San Clemente de Tahull (siglo XIII). 
queado en forma de gancho. E. Oakeshott la fecha entre 1270 y $1350{ }^{68}$. Los ejemplos que ofrecen tanto Ada Bruhn como los demás especialistas pertenecen ya a la segunda mitad del siglo xiv y al siglo $\mathrm{xV}^{69}$. Son espadas con una complejidad formal mucho mayor a las constatadas por nosotros en la iconografía. Todas ellas presentan botón en el pomo, que, como ya se ha dicho, es característica inequívoca del estilo de los siglos xIv y xv. Con frecuencia, se trata de espadas ornamentadas en toda la empuñadura y la hoja es decididamente triangular, característica que no asume ninguno de los ejemplos aquí aportados.

Podemos afirmar que el tipo $\mathrm{V}$ es una forma evolucionada del tipo específicamente románico (tipos II y III) y que en la iconografía catalana aparece con toda seguridad en el siglo XIII. Pero como los ejemplos arqueológicos demuestran, este tipo se utilizó plenamente en los siglos XIV y XV, añadiéndole elementos ornamentales que le situaban dentro de la moda del final de la Edad Media.

TIPO VI: ARriaz EN FORMA DE LENGÜETA

A cualquier estudioso de espadas le sorprenderá por fuerza el tipo VI. La sorpresa reside en el carácter poco específico y poco común del título: arriaz en «forma de lengüeta». En primer lugar, no se introduce aquí, según lo acostumbrado, el tipo del pomo, y en segundo lugar, ningún especialista habla en sus tipologías de «arriaces en forma de lengüeta». La poca formalidad de este título se debe a que se trata de una designación creada por nosotros, y que, consiguientemente, no ha sido aún tipificada. Realmente, la expresión no es excelente, pero corresponde con exactitud a un tipo de espadas cuya característica esencial es la de presentar un arriaz en dicha forma (Fig. 8). Indudablemente, el pomo, en este tipo de espadas, deberá ser considerado como un elemento secundario. Por lo general, suele ser esférico o también discoidal plano, aunque con menor frecuencia. El arriaz, en vez de ser recto, se ensancha por su parte central, adquiriendo una forma puntiaguda, que se introduce en la hoja. Por lo general, sobresale poco de la anchura de la hoja, adoptando, con mucha frecuencia, la forma de gancho. Una espada de este tipo aparece en un capitel de la catedral vieja de Lérida. Presenta un pomo esférico y una hoja también ancha. El arriaz dobla sus extremos ha-

68 Cf. E. OnKESHOTT, op. cit,, pág. 301.

69 Cf. A. BRunn, Middelalderens, cit., t. IT, P1. XXV-XXIX. 
cia el interior y su parte central se alarga en forma triangular (Foto XIX). Este tipo VI cuenta con representaciones tanto escultóricas como pictóricas ${ }^{70}$.

En un primer momento dudamos de la existencia real de este tipo, debido fundamentalmente a que no aparece en ninguna de las

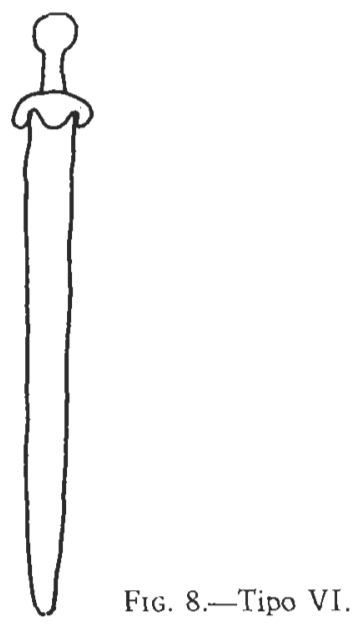

tipologías de los especialistas europeos. Al mismo tiempo parece ser que ningún museo de Europa cuenta con una pieza similar al tipo VI. Sin embargo, no cabe ninguna duda acerca de la existencia de esta espada en Cataluña, pues contamos con una espada real que elimina cualquier tipo de dudas acerca de lo que es «un arriaz en forma de lengüeta». J. E. Cirlot analizó en un artículo una espada de hoja triangular con una empuñadura extraña y con un arriaz idéntico al aquí estudiado ${ }^{71}$. Dicha espada pertenecía por la tipología del pomo y de la hoja al siglo xv. Sin embargo, podemos afirmar que este tipo de arriaz apareció en Cataluña en el siglo XIII, tal y como nos informa la iconografía. Parece ser que este tipo VI constituyó un tipo genuinamente mediterráneo; la ausencia de espadas tipo VI en los museos

70 Cf. Espadas representadas en el Frontal de San Crisióbal (zona derecha) y en la tabla lateral del altar de Tosas (s. XIII).

71 Cf. J. E. Cirlot, ¿Una espada barcelonesa del siglo XV?, en «Gladius», t. X, Madrid, 1973, págs. 9-13. 
del norte y centro de Europa podría corroborar esta hipótesis. De cualquier modo, es ésta una hipótesis que queda abierta a ulteriores investigaciones que permitan fundamentarla con argumentaciones de mayor peso.
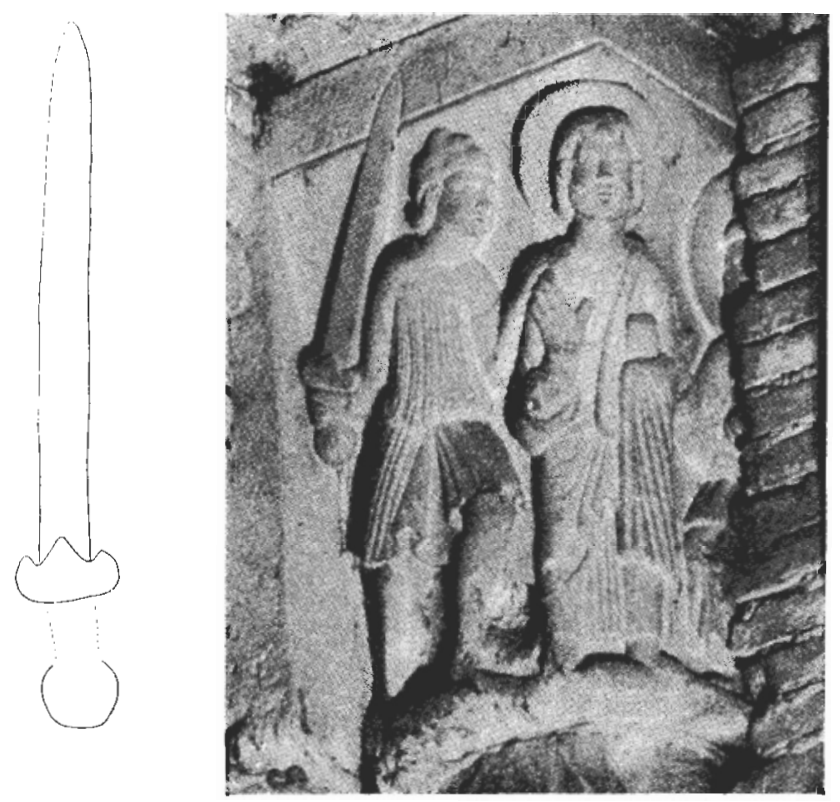

Fото XIX.-Capitel de la catedral vieja de Lérida, interior, s. XIII: Espada tipo VI

\section{Conclusiones}

El análisis tipológico realizado permite obtener una visión de conjunto acerca de la evolución de la espada catalana de los siglos XI al XIII (Fig. 9).

Sin duda alguna, se trata de una visión parcial en muchos aspectos, pero también es verdad que se ha intentado recoger todo aquel material iconográfico que ofreciera ejemplos de espadas. A pesar de que se ha seguido la metodología de los especialistas de armas (en especial de Ada Bruhn), esta tipología ha resultado, en líneas gene- 
rales, distinta. Ello se ha debido, en primer lugar, a que se han constatado tipos que los especialistas no incluyen; en segundo lugar, a que esta tipología se encuentra absolutamente subordinada a las fuentes. Así, los tipos II y IIIa/IIIb constituyen un claro producto

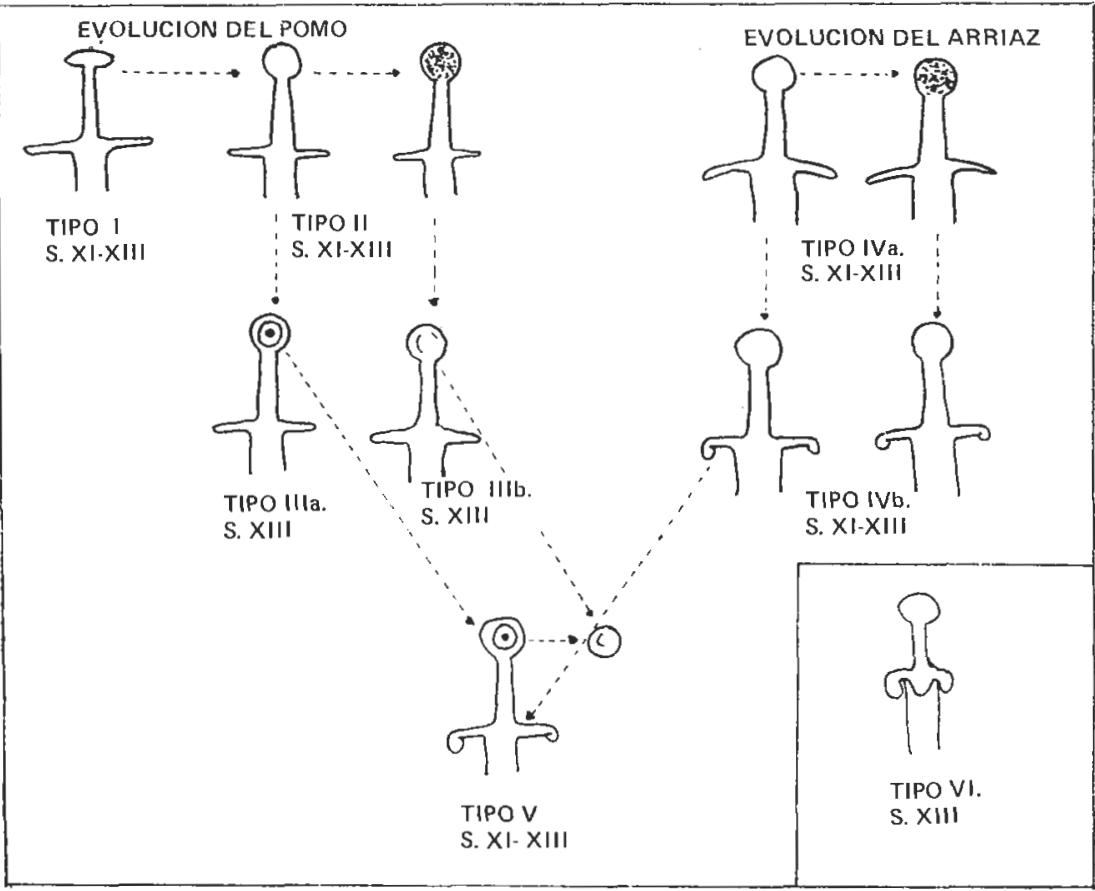

Fig. 9.-Fvolución y cronología de los tipos de espadas en Cataluña

de un análisis iconográfico, en contraposición a lo que sería un análisis basado en piezas arqueológicas.

Pero a pesar de las indudables dificultades que ofrece esta fuente, también se ha puesto de relieve el carácter netamente documental que puede asumir la iconografía. Esta constituye una fuente inestimable para el historiador, en especial para el dedicado a la Edad Media. A través de la obra plástica es posible concebir una sociedad que configura toda su forma de vida simbólicamente, y un análisis estricto 
de su sistema representativo puede desvelar cuestiones fundamentales para la historia de las mentalidades. Pero, al mismo tiempo, se ha podido comprobar la susceptibilidad de este arte para la reconstrucción de los elementos materiales que conformaban el mundo en los siglos XI al XIII.

Según nuestra propia tipología, las espadas del tipo II son las más abundantes en Cataluña, siguiendo en popularidad el tipo IVa y el tipo IIIb. Menos abundantes son el tipo I, el tipo IIIa, el tipo V y el tipo VI, así como el IVb. Sin embargo, no resulta posible intentar un estudio estadístico del tipo de espadas de los siglos XI al XIII, debido a que, en primer lugar, no hemos recogido todo el material iconográfico existente $\mathrm{y}$, en segundo lugar, la iconografía no tiene por qué responder, en este sentido, a la realidad. Posiblemente los tipos II y IVa sean los más frecuentes por tratarse de los tipos más sencillos y más aptos a la pintura, fuente de la que sí se ha utilizado todas las representaciones de espadas, y no así de la escultura o miniatura. De otro lado, el tipo I es poco frecuente debido a la escasez iconográfica que caracteriza a la Cataluña del siglo xI. La complejidad formal mayor que presentan los otros tipos impediría una frecuencia mayor de su representación. Parece que el tipo IIIb se adapta perfectamente al estilo románico, así como también los tipos II y IVa. Hay que tener en cuenta que la espada románica típica perduró hasta los siglos XIV y $\mathrm{xv}$, a pesar de las transformaciones radicales que sufrió el armamento al filo del 1300. Los tipos posrománicos (utilizados con la espada gótica típica) se distinguían de los románicos en el aditamento de ornamentaciones e inscripciones propias de la época. En Cataluña, los tipos netamente románicos se continúan utilizando hasta el 1320, tal y como demuestra la pintura mural de la conquista de Mallorca y algunos otros ejemplos extraídos de sellos. En general, la tipología y cronología establecida por nosotros se adapta a las elaboradas por los especialistas europeos.

No hay que ocultar que hemos tropezado con algunas dificultades en la interpretación de algunas representaciones de espadas, especialmente de las que se encuentran en las Biblias. Muchas de ellas presentaban indudables influencias del mundo oriental. De cualquier forma, por el momento no nos es posible aportar nada decisivo acerca de esta cuestión; en primer lugar, porque el tema occidentalismoorientalismo desborda nuestras posibilidades actuales de análisis, y en segundo lugar, porque la dificultad de interpretación y los numerosos problemas que entrañan las Biblias de Roda y de Ripoll sólo podrían aclararse mediante un estudio muy detallado de todas las piezas del armamento que en ellas aparecen representadas. De todas 
formas, el estudio comparativo que aquí hemos realizado entre los tipos constatados en el arte románico y las espadas reales junto con sus representaciones del resto de Europa permiten afirmar que no se ha encontrado ningún tipo específicamente catalán y que las espadas catalanas de los siglos XI al XIII representaban un carácter occidental y eran idénticas a las demás espadas utilizadas en el resto del Occidente europeo. 